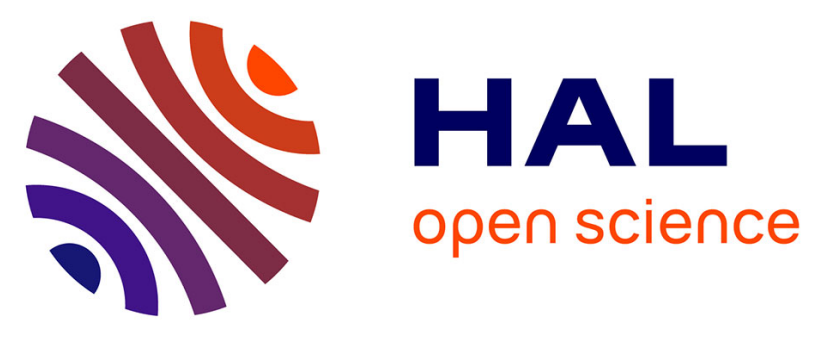

\title{
Experimental and computational study of the gas-phase interactions between lead(II) ions and two pyrimidic nucleobases: Uracil and thymine
}

Sébastien Guillaumont, Jeanine Tortajada, Jean-Yves Salpin, Al Mokhtar

Lamsabhi

\section{To cite this version:}

Sébastien Guillaumont, Jeanine Tortajada, Jean-Yves Salpin, Al Mokhtar Lamsabhi. Experimental and computational study of the gas-phase interactions between lead(II) ions and two pyrimidic nucleobases: Uracil and thymine. International Journal of Mass Spectrometry, 2005, 243 (3), pp.279-293. 10.1016/j.ijms.2005.03.011 . hal-00068623

\section{HAL Id: hal-00068623 \\ https://hal.science/hal-00068623}

Submitted on 5 Oct 2018

HAL is a multi-disciplinary open access archive for the deposit and dissemination of scientific research documents, whether they are published or not. The documents may come from teaching and research institutions in France or abroad, or from public or private research centers.
L'archive ouverte pluridisciplinaire HAL, est destinée au dépôt et à la diffusion de documents scientifiques de niveau recherche, publiés ou non, émanant des établissements d'enseignement et de recherche français ou étrangers, des laboratoires publics ou privés. 


\title{
Experimental and computational study of the gas-phase interactions between
}

\section{Lead(II) ions and two pyrimidic nucleobases : uracil and thymine}

\author{
Sébastien Guillaumont, Jeanine Tortajada and Jean-Yves Salpin* \\ Laboratoire Analyse et Environnement. CNRS UMR 8587, Université d'Evry Val d'Essonne, \\ Boulevard François Mitterrand 91025 Evry Cedex- France
}

\begin{abstract}
Al Mokhtar Lamsabhi
Departamento de Química, C-9, Universidad Autónoma de Madrid, Cantoblanco, 28049-Madrid, Spain
\end{abstract}
Corresponding author: Jean-Yves Salpin
Tel: 33169477647 Fax: 33169477655
e-mail : Jean-Yves.Salpin@ chimie.univ-evry.fr

Number of pages (including Tables, Figures, legends and schemes) : 40

\begin{abstract}
The gas-phase reactivity of lead(II) ions towards uracil and thymine has been studied by means of mass spectrometry and theoretical calculations. Positive-ion electrospray spectra show that this reactivity gives rise to both singly and doubly-charged species. The singly charged $[\mathrm{Pb} \text { (nucleobase })_{\mathrm{n}}$ $-\mathrm{H}]^{+}(\mathrm{n}=1-4)$ complexes are the most intense ions on spectra at low concentration and are produced notably by dissociative proton transfer within the doubly charged $\left.[\mathrm{Pb} \text { (nucleobase) })_{\mathrm{m}}\right]^{2+}(\mathrm{m}=6-12)$ complexes. The most abundant ion, $[\mathrm{Pb} \text { (nucleobase) }-\mathrm{H}]^{+}$, has been extensively studied by MS/MS experiments. Results obtained with uracil and thymine are rigorously similar and show that this ion mainly dissociates by elimination of isocyanic acid, and by formation of a $[\mathrm{PbNCO}]^{+}$ion. According to labeling experiments, the $\mathrm{N} 3, \mathrm{C} 2$ and $\mathrm{O} 2$ centers are exclusively expelled and complexed, respectively. Our experimental data suggest that the complex may correspond to a mixture of several structures. This is supported by stability of the most stable minima which are close in energy. Comparison with the geometry of neutral and deprotonated nucleobases indicates that lead cationization induces significant geometrical modifications, and more particularly an important activation of the N3-C4 bond, which accounts for the observed fragmentations.
\end{abstract}




\section{Introduction}

Lead is recognized as a toxic element for more than two centuries now [1]. Indeed, this metal can induce severe damage to human health. It has been established that alkylleads are rapidly metabolized and readily cross the blood-brain barrier. These physicochemical properties makes the central nervous system the main site of their toxic action [1]. However, lead can also affect almost every organ in the human body, such as the liver, kidneys or heart. This element also affects the homeostasis of many other metal ions like $\mathrm{Ca}^{2+}, \mathrm{Zn}^{2+}$ or $\mathrm{Cu}^{2+}$ [2,3]. In biological systems, the only important oxidation state of lead is $\mathrm{Pb}^{2+}$. Different works have demonstrated that the toxicity of this metal ions is mainly due to its interactions with nucleic acids. It has been shown for example that Lead(II) ions are much more efficient in RNA depolymerisation than many other metal ions such as $\mathrm{Zn}^{2+}, \mathrm{Hg}^{2+}$ or $\mathrm{Co}^{2+}[4]$. The $\mathrm{Pb}^{2+}-$ induced hydrolysis of RNA is widely studied [5-7], and the leadzyme was demonstrated as a small RNA motif, that catalyses a site-specific, $\mathrm{Pb}^{2+}$ dependent cleavage reaction [7-9]. Destabilization of DNA structure has been also reported [10,11].

Despite the known effects of $\mathrm{Pb}^{2+}$ on the structure and stability of nucleic acids, the coordination chemistry between Lead(II) ions and nucleosides/nucleotides is relatively poorly documented. One reasonable way of approaching this chemistry is by exploring the behavior of small model systems. In this context, several papers dealing with the reactivity in aqueous solution of $\mathrm{Pb}^{2+}$ ions with simple phosphates, phosphonates [12] and nucleotides [13,14], have been recently published by Sigel and co-workers. Up to now and to our knowledge, these systems have not been studied in the gas-phase. Yet, such studies would allow to obtain useful information about the fundamental binding modes of Lead(II) ions to the various components of nucleic acids (phosphate groups, sugars, nucleobases). For these reasons, we have begun an exhaustive study on the gas-phase reactivity observed between $\mathrm{Pb}^{2+}$ ions and nucleic acids, 
and the present paper reports the first results obtained with two nucleobases : thymine and uracil (scheme 1).

$<$ Scheme 1>

This work has been done by combining mass spectrometry experiments and theoretical calculations. From the experimental point of view, the development of electrospray ionization techniques has opened up the possibility of producing organometallic complexes in the gas phase from aqueous solutions [15], and therefore of gaining direct information on the intrinsic reactivity of organic molecules when interacting with metal dications. However, in order to obtain a complete picture of the reactivity patterns one needs to have not only experimental information on the products distribution but also postulate appropriate reaction mechanisms. This was presently achieved by combining mass spectrometry experiments with theoretical DFT calculations by making use of two density functionals methods: B3LYP and G96LYP.

\section{Experimental details}

Electrospray mass spectra were recorded on an Applied Biosystems/MDS Sciex API2000 triple-quadrupole instrument fitted with a "turboionspray" ion source. Solutions of Lead nitrate/nucleobase at various concentrations were prepared either in pure water (purified with a Milli-Q water purification system) or in a water/methanol mixture $(50 / 50 \mathrm{v} / \mathrm{v})$, and were introduced in the source using direct infusion with a syringe pump, at a flow rate of 5 $\mu \mathrm{l} / \mathrm{min}$. Ionization of the samples was achieved by applying a voltage of $5.5 \mathrm{kV}$ on the sprayer probe and by the use of a nebulizing gas (GAS1, air) surrounding the sprayer probe, intersected by a heated gas (GAS2, air) at an angle of approximately $90^{\circ}$. The operating pressure of GAS1 and GAS2 are adjusted to 2.1 bars, by means of an electronic board (pressure sensors), as a fraction of the air inlet pressure. The curtain gas $\left(\mathrm{N}_{2}\right)$, which prevents 
air or solvent from entering the analyser region, was similarly adjusted to a value of 1.4 bars. The temperature of GAS2 was set at $100^{\circ} \mathrm{C}$.

MS/MS spectra were carried out by introducing nitrogen as collision gas in the second quadrupole at a total pressure of $3 \times 10^{-5}$ mbar, the background pressure being around $10^{-5}$ mbar. It is worth mentioning that given the length of the second quadrupole and the pressure of nitrogen, a multiple collision regime is very likely and will increase the internal energy content of the parent ion. As detailed later, the declustering potential (DP), defined as the difference of potentials between the orifice plate and the skimmer (grounded), and typically referred to as the "cone voltage" for other electrospray interfaces, was fixed to $60 \mathrm{~V}$ to perform MS/MS experiments. Furthermore, MS/MS spectra were recorded at different collision energies (the kinetic energy of ions is given by the difference of potentials between the focusing quadrupole Q0 preceding Q1, and the collision cell Q2).

Unless otherwise noted, mass to charge ratios mentioned in throughout this paper refer to as peaks which include the most abundant Lead isotope $\left({ }^{208} \mathrm{~Pb}\right)$. Nucleobases and Lead nitrate were purchased from Aldrich and were used without further purification.

\section{Computational details}

Molecular orbital DFT calculations were carried out using B3LYP and G96LYP density functionals, as implemented in the Gaussian-98 set of programs [16]. B3LYP and G96LYP combines the non local correlation function of Lee, Yang and Parr [17], with the Becke's three-parameter non local hybrid exchange functional [18] and the 1996 exchange functional of Gill [19], respectively.

The different structures have first been optimized with the dp-polarized 6-31G(d,p) basis set for $\mathrm{C}, \mathrm{H}, \mathrm{N}$ and $\mathrm{O}$ atoms. The different structures were fully optimized without the constraint on a possible planarity. Harmonic vibrational frequencies were estimated at this level to 
classify the stationary points as local minima or saddle points, and to estimate the zero-point vibrational energy (ZPVE) corrections. To determine the connectivity between each transition structure and its adjacent minima, we have used the intrinsic reaction coordinate (IRC) procedure [20], as implemented in Gaussian 98. Finally, relative energies were determined using the extended basis set $6-311+\mathrm{G}(3 \mathrm{df}, 2 \mathrm{p})$.

Different effective core potentials have been proposed in the literature for $\mathrm{Pb}$. In the present study, we used the "Stuttgart" quasi-relativistic pseudo-potential developed by Küchle et al [21]. This particular ECP employs a $(4 s, 4 p, 1 d) /[2 s, 2 p, 1 d]$ basis set with a $(3,1)$ contraction scheme for $s$ and $p$ functions. Hence, this basis set can be used directly in conjunction with the standard 6-31G(d,p) Pople basis set of C, N, O and H, for geometry optimization.

To perform calculations at a higher level of theory, we recently developed [22] 6-311+G(2df) and $6-311+\mathrm{G}(3 \mathrm{df})$ extended basis sets to be used in conjunction with a couple of pseudopotentials. During this study, it has been established that these basis sets, when combined with the G96LYP/Stuttgart approach, yield binding enthalpies in close agreement with those obtained at the QCISD(T)/Stuttgart and $\operatorname{CCSD}(\mathrm{T}) /$ Stuttgart levels of theory, but at a significantly lower cost. Finally, it turned out that G96LYP/Stuttgart and B3LYP/Stuttgart approaches provide a good compromise between accuracy and computational cost in the calculation of binding energies. Moreover, B3LYP has been found well suited both for description of ion-molecule complexes [23-25] and for the study of inter- and intra-molecular hydrogen bonds [25-28]. Consequently these different reasons lead us to carry out both B3LYP and G96LYP calculations.

For simplicity in nomenclature, the basis sets used for $\mathrm{Pb}$ in conjunction with the $6-31 \mathrm{G}(\mathrm{d}, \mathrm{p})$ and $6-311+\mathrm{G}(3 \mathrm{df}, 2 \mathrm{p})$ for the remaining atoms, will now be referred to as 6-31G(d,p) and 6-311+G(3df,2p) basis sets respectively. 
To give a picture of the distribution of charge within the different species, we have carried out a natural population analysis (NPA) at the B3LYP/6-31G(d,p) level by means of the NBO program for all the structures investigated [29]. The bonding within the individual equilibrium structures was also analyzed by locating the bond critical points (bcps) using atoms-inmolecules (AIM) theory [30], which is based on a topological analysis of the charge density. The electron density at the bcps is a good measure of the strength of the bond.

Throughout this paper total energies are expressed in hartree and relative energies in $\mathrm{kJ} / \mathrm{mol}$. Unless otherwise noted, the relative energies given hereafter are those obtained at a level equivalent to either B3LYP/6-311+G(3df,2p)//B3LYP/6-31G(d,p)+ZPE or G96LYP/6311+G(3df,2p)//G96LYP/6-31G(d,p)+ZPE. Detailed geometries of all the structures mentioned in this paper (neutral nucleobases, uracilates, thyminates and $\mathrm{Pb}^{2+}$-complexes) are available upon request.

\section{Results-discussion}

Positive ion electrospray spectra of $\mathrm{Pb}\left(\mathrm{NO}_{3}\right)_{2} /$ nucleobase mixture. Typical positive-ion electrospray spectra of an aqueous mixture of Lead nitrate and thymine recorded with a DP of $40 \mathrm{~V}$, are given in Figure 1a and 1b. Because of its specific isotopic distribution, peaks involving one lead atom can be easily recognized as they correspond to characteristic triplets (to simplify, we shall not consider the very weak ${ }^{204} \mathrm{~Pb}$ contribution). Electrospray spectra were recorded at different concentrations and at various DP ranging from 0 to $200 \mathrm{~V}$.

Comparison of the two spectra shows that the nature of the ions detected is concentrationdependent. At low DP, the low-mass region is characterized by a series of ions due to protonation of solvent. At high concentration $\left(10^{-3}\right.$ mol. $\mathrm{L}^{-1}$, Figure $\left.1 \mathrm{~b}\right)$, these ions are so overwhelming that one has to start scanning the mass range at $\mathrm{m} / \mathrm{z} 100$ to detect the other 
species in significant abundance. On the other hand, at low concentration (Figure 1a) ions arising from protonation of solvent are progressively removed as the DP is increased.

Peaks corresponding to the protonated nucleobase ([Thymine] $\mathrm{H}^{+}$at $\mathrm{m} / \mathrm{z} 127$ and the proton bound homodimer [Thymine $]_{2} \mathrm{H}^{+}$at $\mathrm{m} / \mathrm{z}$ 253) are systematically detected. This was expected given the quite high gas-phase basicity of these nucleobases. At high concentration their abundance is particularly important, the $\mathrm{m} / \mathrm{z} 127$ ion being the base peak whatever the source/interface energetic conditions used.

From Figure $1 \mathrm{a}$ and $1 \mathrm{~b}$, we can see that the electrospray spectrum, at $\mathrm{DP}=40$ volts, also presents hydrated lead hydroxide ions $\mathrm{PbOH}^{+} \cdot \mathrm{xH}_{2} \mathrm{O}$ at $\mathrm{m} / \mathrm{z} 225$ and 243 (x in fact ranges between 0 and 5, depending on both the concentration of Lead nitrate and the cone voltage). When diluted solutions are infused, increasing the declustering potential up to $200 \mathrm{~V}$ results in the gradual removal of hydrated hydroxide ions, bare lead ion $\mathrm{Pb}^{+}(\mathrm{m} / \mathrm{z} 208)$ being the base peak at the highest DP.

Interaction between lead(II) ions and thymine (or uracil) gives rise to four distinct series of ions. The first one correspond to $\left[\mathrm{Pb}(\text { thymine })_{\mathrm{n}}-\mathrm{H}\right]^{+}(\mathrm{n}=1-4)$ species (at $\mathrm{m} / \mathrm{z} 333,459,585$ and 711 in Figure 1). Their intensities vary with the concentration. At $10^{-3}$ mol. $\mathrm{L}^{-1}$ (Figure 1b), the $[\mathrm{Pb}$ (thymine $)-\mathrm{H}]^{+}(\mathrm{m} / \mathrm{z} 333)$ is weak whilst it is the most intense complex in Figure 1a. This ion can be also solvated especially at high concentrations (Figure 1b) as attested by the detection of m/z 351, 369 and 387 ions. Furthermore, comparison of MS/MS spectra obtained with uracil and thymine lead us to conclude that the third series at $\mathrm{m} / \mathrm{z} 522,648,774$ and 900 can be unambiguously attributed to $\left[\mathrm{Pb}(\text { nucleobase })_{\mathrm{n}}-\mathrm{H}\right]^{+} \cdot \mathrm{HNO}_{3}$ complexes.

Finally, we managed to detect at high concentration doubly-charged complexes of the type $\left.[\mathrm{Pb} \text { (nucleobase })_{\mathrm{m}}\right]^{2+}(\mathrm{m}=6-12)$. These species exhibit the same behavior upon collision than hydrated divalent metal ions. Two dissociation channels are observed : (i) dissociative proton transfer to generate $\left[\mathrm{Pb}(\text { nucleobase })_{\mathrm{n}}-\mathrm{H}\right]^{+}$ions $(\mathrm{n}=1-4$, depending on $\mathrm{m})$ together with 
(nucleobase) $)_{\mathrm{p}} \mathrm{H}^{+}(\mathrm{p}=1$ or 2$)$, (ii) elimination of one or several nucleobase units leading to doubly charged ions, the latter process being dominant for the heaviest precursor ions. During these MS/MS experiments, the smallest doubly charged complex detected was $\left.[\mathrm{Pb} \text { (nucleobase })_{2}\right]^{2+}$. However, formation of a species in which $\mathrm{Pb}^{2+}$ interacts with a single ligand can't be rigorously ruled out. Indeed such systems, although thermodynamically unstable with respect to charge transfer, might be generated under electrospray conditions as illustrated by the recent observation of a m/z 113 ion attributed to $\left[\mathrm{Pb}\left(\mathrm{H}_{2} \mathrm{O}\right)\right]^{2+}[31]$. Consequently, it turns out that there is a competition between protonation of nucleobases and interaction with the metallic center. Observation of very intense lead/nucleobase complexes is rather achieved with both diluted concentrations and low DP values (between 40 and 60 volts) . It is worth noting that in the case of these two particular nucleobases (uracil and thymine), observation of organometallic complex is rather straightforward. This situation is radically different with cytosine, guanine and adenine [32] which are much more basic than uracil and thymine, and for which protonation is clearly overwhelming. Several attempts were made in order to limit the protonation process. This can be partly achieved at low concentrations, but also by changing for example the metal/lingand ratio or by using a water/methanol mixture instead of pure water. Note that MS/MS spectra of the various complexes do not depend on the solvent composition.

MS/MS experiments have also demonstrated that the $[\mathrm{Pb} \text { (thymine) }-\mathrm{H}]^{+}$ion (m/z 333, Figure 1) also originates from higher homologues by successive losses of one, two or three nucleobase units. This species may be also generated from the following processes :

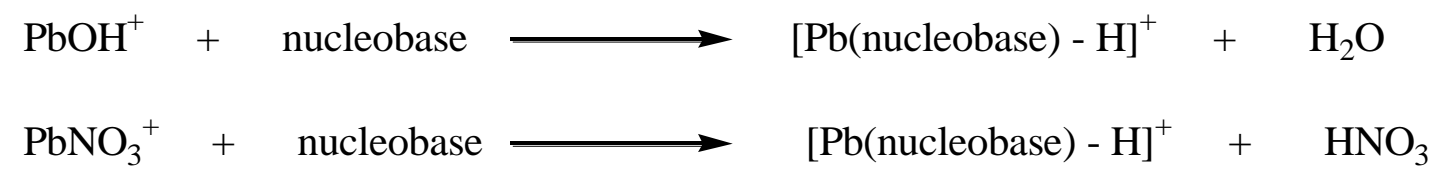


Indeed, according to B3LYP/6-311+G(3df,2p)//B3LYP/6-31G(d,p) calculations, these reactions are exothermic by 76 and $47 \mathrm{~kJ} \cdot \mathrm{mol}^{-1}$ for uracil, respectively, while similar values are obtained for thymine (71 and $50 \mathrm{~kJ}^{\mathrm{mol}}{ }^{-1}$, respectively). Our theoretical study has demonstrated that $\mathrm{PbOH}^{+}$ion, when approaching either $\mathrm{N} 3$ or $\mathrm{N} 1$, induces a significant $\mathrm{N}-\mathrm{H}$ bond elongation. This might result in the formation of a $[\mathrm{Pb} \text { (nucleobase) }-\mathrm{H}]^{+} \cdot \mathrm{H}_{2} \mathrm{O}$ intermediate followed by elimination of water. Note that $[\mathrm{Pb}$ (nucleobase) $-\mathrm{H}] \cdot \mathrm{H}_{2} \mathrm{O}^{+}$ions are detected (m/z 351 in Figure 1). Reaction 2 is supported by the observation of both $\mathrm{PbNO}_{3}{ }^{+}$ and $\left[\mathrm{Pb}(\text { nucleobase })_{\mathrm{n}}-\mathrm{H}\right]^{+} . \mathrm{HNO}_{3}$ ions on spectra, the latter ions loosing nitric acid under MS/MS conditions. In addition, a Car-Parrinello/molecular dynamics simulation [33,34] has shown that deprotonation in aqueous solution of the nucleobase by a strong base such as hydroxide ions $\mathrm{OH}^{-}$, followed by a direct attack of $\mathrm{Pb}^{2+}$ ions onto the newly formed anion, could lead to the $[\mathrm{Pb} \text { (nucleobase) }-\mathrm{H}]^{+}$complex. Conversely, one may reasonably rule out the direct endothermic proton abstraction reaction (equation 3) :

$$
\mathrm{Pb}^{2+}+\text { nucleobase } \longrightarrow \quad[\mathrm{Pb} \text { (nucleobase) }-\mathrm{H}]^{+}+\mathrm{H}^{+}
$$

In summary, the $[\mathrm{Pb} \text { (nucleobase) }-\mathrm{H}]^{+}$ion is the most abundant species resulting from the interaction between the $\mathrm{Pb}^{2+}$ cation and a single nucleobase and the paper will now focus on its structural characterization, by means of MS/MS experiments, labeled reactants and theoretical calculations. This ion will now be referred to as $[\mathrm{Pb}(\mathrm{U})-\mathrm{H}]^{+}$and $[\mathrm{Pb}(\mathrm{T})-\mathrm{H}]^{+}$for uracil and thymine, respectively.

Low-energy CID spectra of $[\mathrm{Pb} \text { (nucleobase) }-\mathbf{H}]^{+}$ion. $[\mathrm{Pb} \text { (nucleobase)-H}]^{+}$species involving ${ }^{208} \mathrm{~Pb}$ were selected and allowed to dissociate upon collision with nitrogen. MS/MS spectra were recorded at different collision energies between 1 to $30 \mathrm{eV}$ in the laboratory frame. The MS/MS spectrum obtained for $[\mathrm{Pb}(\mathrm{U})-\mathrm{H}]^{+}$ion at $\mathrm{E}_{\mathrm{lab}}=20 \mathrm{eV}$ (which corresponds to a collision energy of $1.6 \mathrm{eV}$ in the center of mass frame) is given in Figure 2a. The 
complexation (structure, energetics) of nucleobases with metal ions has been extensively investigated [35-53], while the gas-phase unimolecular reactivity of metal/nucleobase complexes has been only scarcely studied, and we will try to compare these results with those deduced from previous studies.

For both $[\mathrm{Pb} \text { (nucleobase) }-\mathrm{H}]^{+}$complexes, a whole set of MS/MS spectra, including precursor ion scan mode and neutral loss experiments, lead to the following fragmentation pattern (Scheme 2)

$<$ Scheme 2>

These data demonstrate that $[\mathrm{Pb}(\mathrm{U})-\mathrm{H}]^{+}$and $[\mathrm{Pb}(\mathrm{T})-\mathrm{H}]^{+}$ions present exactly the same unimolecular reactivity upon collision, so that we will now concentrate on the results obtained with uracil. Decomposition of $[\mathrm{Pb}(\mathrm{U})-\mathrm{H}]^{+}$ions is characterized by the cleavage of the pyrimidic ring. Indeed, the two main primary fragmentations correspond to (i) loss of a $[\mathrm{H}, \mathrm{N}, \mathrm{C}, \mathrm{O}]$ molecule $(\mathrm{m} / \mathrm{z} 276)$ and (ii) formation of a m/z 250 ion, attributed to [Pb,N,C,O $]^{+}$. The loss of $[\mathrm{H}, \mathrm{N}, \mathrm{C}, \mathrm{O}]$ is also important for $[\mathrm{M}(\text { uracil) })-\mathrm{H}]^{+}$and $[\mathrm{M} \text { (thymine) }-\mathrm{H}]^{+}$ions generated under electrospray conditions ( $\mathrm{M}$ being $\mathrm{Mg}$ [54] or $\mathrm{Cu}$ [55]). Unsurprisingly, this reactivity dramatically differs from that of complexes formed by the interaction between a monocation and an intact nucleobase. Indeed, $[\mathrm{M}(\text { uracil })]^{+}$and $[\mathrm{M}(\text { thymine })]^{+}(\mathrm{M}=\mathrm{Li}, \mathrm{Na}, \mathrm{K}$, $\mathrm{Mg}$ ) react almost exclusively by loss of the intact molecule according to several experimental studies[41,56]. Finally, we also observe the direct formation of $[\mathrm{PbOH}]^{+}$ions. This may suggest the presence of a small amount of tautomeric forms of uracil or thymine.

These results show the reactivity upon collision of metal/nucleobases complexes involving monocations or dications is radically different. The same is found when we examine the dissociations of protonated uracil or thymine. The only common fragmentation observed for $[\mathrm{Pb} \text { (nucleobase) }-\mathrm{H}]^{+}$and [nucleobase $] \mathrm{H}^{+}$ions is the elimination of $[\mathrm{H}, \mathrm{N}, \mathrm{C}, \mathrm{O}]$. The protonated species is characterized by loss of ammonia, and to a minor extent, water. Note that these 
three processes have been already observed during the collision-induced dissociation of both protonated uracil and thymine produced by FAB ionization [57].

In order to propose reliable mechanisms for the main fragmentations, and subsequently structures for the $[\mathrm{Pb} \text { (nucleobase) }-\mathrm{H}]^{+}$ions, we have undertaken additional MS/MS experiments using labeled nucleobases. The resulting spectra are presented in Figure $\mathbf{2 b - d}$ and the results are summarized in Table 1.

Elimination of $[H, N, C, O]$

One may reasonably assume that elimination of 43 Daltons without extensive rearrangement requires adjacent atoms to be expelled. In that case isocyanic $(\mathrm{H}-\mathrm{N}=\mathrm{C}=\mathrm{O})$ acid should be eliminated instead of cyanic acid $(\mathrm{HO}-\mathrm{C} \equiv \mathrm{N})$. According to Scheme 3, this may correspond to three distinct cleavages.

$<$ Scheme 3>

Use of labeled compounds proved to be particularly useful to determine if loss of 43 Daltons implies one or several mechanisms (Figure 2). Firstly, we can notice that whatever the labeled nucleobase studied, elimination of $\mathrm{HNCO}$ corresponds to a single peak in the spectra (Figure 2b-d). This supports the assumption of adjacent atoms eliminated. Second, our set of MS/MS experiments (Table 1) clearly demonstrates that the loss of HNCO involves exclusively the elimination of the $\mathrm{C} 2$ and $\mathrm{N} 3$ atoms. Consequently, the elimination of isocyanic acid exclusively occurs via cleavage $\mathbf{2}$ and seems to involve a structure in which N3 is not deprotonated.

\section{Formation of $[\mathrm{Pb}, \mathrm{N}, \mathrm{C}, \mathrm{O}]^{+}$}

Three cleavages can also lead to formation of $[\mathrm{Pb}, \mathrm{N}, \mathrm{C}, \mathrm{O}]^{+}$ions. Again, we can see (Figures 2b-d) that this fragmentation corresponds to a single peak on MS/MS spectra, regardless of the labeled compound studied. This suggests that the N,C,O moiety is made of adjacent 
atoms, and the mass to charge ratios observed on the four spectra unambiguously indicate that these atoms are $\mathrm{C} 2$ and N3, and very likely the oxygen $\mathrm{O} 2$ (Scheme 1).

In summary, the data obtained with labeled nucleobases gave useful information concerning the two main fragmentations. Moreover, comparison of the results obtained for the two main fragmentation processes suggest that a mixture of a least two $[\mathrm{Pb}(\text { nucleobase })-\mathrm{H}]^{+}$structures are generated in the gas-phase.

Computational study. In order to rationalize these experimental findings, we have carried out theoretical calculations that enable us to discuss the topology of the $[\mathrm{Pb} \text { (nucleobase) }-\mathrm{H}]^{+}$ potential energy surfaces, as well as the structures and bonding characteristics of the most stable complexes. Precursor ions having a sufficient lifetime to reach the second quadrupole should be stable prior to collisional activation. Furthermore, the intensity of $[\mathrm{Pb}$ (nucleobases) $-\mathrm{H}]^{+}$remains significant at high cone voltage. So we have considered that the $[\mathrm{Pb} \text { (nucleobase) }-\mathrm{H}]^{+}$ions were stable species and that our experiments could be carried out in conjunction with ground state theoretical calculations.

Uracil and thymine may exist in various tautomeric forms differing from each other by the position of the protons which may be bound to either nitrogen or oxygen atoms. As the difference in energy between both uracil and thymine tautomers is quite important in the gasphase [58-61], the population of the most stable tautomer (2,4-dioxo) should be clearly overwhelming. However, in order to perform a detailed description of the $[\mathrm{Pb} \text { (uracil) }-\mathrm{H}]^{+}$ and $[\mathrm{Pb}$ (thymine $)-\mathrm{H}]^{+}$systems, we also took into account 2-hydroxy-4-oxo and 2-oxo-4hydroxy tautomeric forms, which are about $50 \mathrm{~kJ} \mathrm{~mol}^{-1}$ higher in energy than the 2,4-dioxo forms. We also studied mono- and di-coordination modes and we considered that deprotonation could formally occur on several sites : nitrogens, $\mathrm{C}(5)$ (for uracil) and oxygens for tautomeric forms. On the other hand, we decided not to investigate in detail $\pi$-interactions because recent theoretical studies on alkaline [41,50] and alkaline earth [50] metals have 
demonstrated that $\pi$-interactions induce an important distortion of the aromatic ring from planarity that destroys much of the resonance delocalization and lead to high-energy species. Note that we managed to locate for the $[\mathrm{Pb} \text { (uracil) }-\mathrm{H}]^{+}$ion a $\pi$-complex which lies 225 $\mathrm{kJ} . \mathrm{mol}^{-1}$ above the global minimum.

B3LYP and G96LYP total and relative energies of the different structures obtained for uracil and thymine are summarized in Tables 2 and 3, respectively. For both uracil and thymine, structures are labeled as described in Figure 3. The capital letters $\mathbf{U}$ and $\mathbf{T}$ stand for Uracil and Thymine, respectively, while the small letter $\mathbf{t}$ is added for tautomeric forms. Relevant bond lengths of the three most stables structures are given in Figures 5 and 6, together with the most stable forms of both neutral and deprotonated nucleobase.

All the structures given in Tables 2 and 3 are characterized by a metal which lies in the same plane than the nucleobase. Furthermore, the aromaticity of the nucleobase is preserved as the ring is absolutely not distorted. We can see from these two tables that the energy differences between the most stable structures are small ( 6 structures within $50 \mathrm{~kJ} / \mathrm{mol}$ ), and do not vary significantly with the level of calculation. This is in favor of a mixture of several structures in the gas-phase. Moreover, the same order is obtained regardless of the density functional considered. Secondly, the most stable forms always correspond to bicoordinated species. The only monocoordinated minima (U10t and T10t) are about $180 \mathrm{~kJ} / \mathrm{mol}$ higher in energy than the global minima (U1, T1). U10t and T10t formally correspond to the interaction between a $\mathrm{Pb}^{2+}$ ion and a deprotonated non canonical 2-hydroxo-4-oxo tautomer. These results are different from those reported for alkali metals $[35,41,43,45,50,62], \mathrm{Mg}^{+}[56], \mathrm{Mn}^{2+}[46]$ or $\mathrm{Cu}^{2+}[63]$, which are indeed preferentially coordinated to the $\mathrm{O} 4$ atom. Bidentate interactions correspond to the most stable structures with alkaline earth metal cations [47] and $\mathrm{Cu}^{+}$[64], but they imply tautomeric forms of the nucleobases. In the present work, bicoordinated species involving the canonical form (2-oxo-4-oxo) of uracil (U1, U2 and U3) or thymine 
(T1, T3 or T3) are found to be the most stable because deprotonation of the nucleobase occurs during the complexation process. On the other hand, $\mathrm{Pb}^{2+}$ ions behave like alkali earth metal cations when interacting with intact uracil or thymine [65].

Results obtained with uracil and thymine are similar. The global minimum (U1 or T1) is characterized by an interaction between the metallic center and both $\mathrm{N} 3$ and $\mathrm{O} 4$ atoms. The two most stable forms imply that deprotonation occurs at the N3 position, which corresponds to the least acidic amino group in the gas-phase [66-71]. Several experimental and theoretical studies $[68,72-74]$ have shown that the N1 and N3 sites are of similar acidity in water while $\mathrm{N} 1$ is the most acidic site in the gas-phase (coalescence effect). This effect might account for the formation of $\mathbf{U 1}$ (and also $\mathbf{U} \mathbf{2}$ and $\mathbf{U 3}$ ) if one assumes that part of the $[\mathrm{Pb} \text { (uracil)- } \mathrm{H}]^{+}$ions observed are generated in solution according a two step processes: 1) deprotonation of the nucleobase by a strong base such as hydroxide ions $\mathrm{OH}^{-}$, followed by 2) a direct attack of $\mathrm{Pb}^{2+}$ ions onto the newly formed. This assumption is supported by recent Car-Parrinello simulations carried out in our laboratory [33].

Note also that $[\mathrm{Pb} \text { (uridine) }-\mathrm{H}]^{+}$and $[\mathrm{Pb} \text { (thyminidine) }-\mathrm{H}]^{+}$complexes are known to be formed upon deprotonation of the $\mathrm{N} 3(\mathrm{H})$ in the alcaline $\mathrm{pH}$ range $[14,75]$.

Examination of Table 2 shows that the structure involving deprotonation at the C5 carbon is highly energetic. Tautomeric forms are also less stable than the U1-U3 forms, but the difference in energy is relatively small when the metal interact with a carbonyl group. On the other hand, coordination to a hydroxyl group leads to an energetically unfavorable geometry (U11t and T11t). These result raises the question of the possible formation of such structures in the gas-phase. As the 2,4-dioxo tautomer is predominant not only in the gas-phase but also in solution or in the solid state [76-84], one may wonder if a tautomerization process could be promoted by the metal. In this context, we have estimated the energetics associated with different tautomerization processes and compared the results obtained with the anionic 
counterparts. The potential energy surface associated with tautomerization of N1 deprotonated uracil (dU1) is given in Figure 4a. First, we can see that the relative energies of the minima does not vary with the level of calculation. The gap is slightly more pronounced for the transition states. Furthermore, the energy differences obtained at the B3LYP/6-31G(d,p) level between dU1, dU3t, and dU4t structures $\left(0,+60.4\right.$ and $+78.0 \mathrm{~kJ} \cdot \mathrm{mol}^{-1}$, respectively) are in excellent agreement with the data obtained at the B3LYP/6-31+G(d,p) $(0,+59.4$ and +77.6 $\mathrm{kJ} \mathrm{mol}^{-1}$, respectively) by Kryachko et al [59]. This suggests that the lack of diffuse functions on heavy atoms, which are usually very important for an accurate description of anionic system, does not lead presently to significant errors. The activation barriers associated with the two processes are of similar height than those calculated for isomerization of neutral cytosine $[85,86]$ or thiouracils [87]. The potential energy surface associated with the tautomerization of the corresponding cationized structures is given in Figure 4b. Our data point out that $\mathrm{Pb}^{2+}$-cationization induces the stabilization of the tautomeric forms, provided the metal is coordinated to a carbonyl group (U4t). Indeed, structures $\mathbf{U 3}$ and $\mathbf{U 4 t}$ are degenerated. The corresponding activation barrier is also lowered. On the other hand, formation of a tautomeric form in which the dication interacts with a hydroxyl group (U11t) is clearly unfavorable. This is consistent with dications binding energies that are reported to be substantially larger for carbonyl compounds than for water [88,89], and may also account for the very weak intensity of $\mathrm{PbOH}^{+}$ions on MS/MS spectra, which might arise directly from a structure such as U11t.

In order to characterize the nature of the interactions within these complexes, we have carried out a natural population analysis (NPA) at the B3LYP/6-31G(d,p) level by means of the NBO program for all the structures investigated [29]. The bonding within the individual equilibrium structures was also analyzed by locating the bond critical points (bcps) using atoms-inmolecules (AIM) theory [30]. First, we did not manage to obtain any reliable bcp associated 
with $\mathrm{Pb}-\mathrm{X}(\mathrm{X}=\mathrm{O}$ or $\mathrm{N})$, probably due to the use of a pseudo-potential for the metal. According to the NBO study, the natural bond orbitals associated with $\mathrm{Pb}-\mathrm{X}$ bonds always present a pure $p$-character, mostly centered onto the heteroelement. If we focus on the three most stable structures, NPA charges show a transfer of electrons from the nucleobase moiety to the lead atom, the local charge on Pb being +1.55-1.56 with the B3LYP functional (Table 4), whereas values of 1.49-1.50 e- are deduced from G96LYP calculations. These values are smaller than those determined for $\left[\mathrm{Pb}\left(\mathrm{H}_{2} \mathrm{O}\right)_{4}\right]^{2+}$ ions $(+1.76-1.78)$ [90], thus indicating a greater degree of electron transfer and some covalent character in the metal-ligand interaction. Table 4 also reveals a slight increase of the negative charge for the interacting nitrogen and oxygen. For a given geometry, the electron transfer is slightly more pronounced for thymine than for uracil, thus suggesting the role of the additional methyl group.

Examination of the natural bond orbitals (NBO) shows that the $\mathrm{Pb}(\mathrm{II})$ lone pair is predominantly $6 \mathrm{~s}$, but is slightly polarized by a small $6 \mathrm{p}$ contribution, ranging from 3.2 to 3.6\%. This feature is characteristic of hemi-directed structures, as already noticed by Bock and co-workers [90]. This is confirmed by the bcp associated with the Pb lone pair, always turned toward the opposite side of the ligand. Furthermore, natural electron configuration analysis indicates that the electron transfer is mostly in the 6p orbitals (typical values being : $\left.6 \mathrm{~s}[1.94] 6 \mathrm{p}[0.51] \mathrm{sp}^{0.26}\right)$. The value of 0.26 for $\mathrm{Pb}(\mathrm{II}) \mathrm{sp}$ hybridization, is smaller than the value obtained for the $[\mathrm{Pb}(\mathrm{D} \text {-glucose })-\mathrm{H}]^{+}$complex [91], thus suggesting that the bonding is presently more electrostatic than with monosaccharides.

\section{Unimolecular reactivity of $[\mathrm{Pb}(\text { nucleobase })-\mathrm{H}]^{+}$complexes .}

The electron transfer from the nucleobase to lead cation induces significant geometrical modifications as illustrated in Figures 5 and 6 for the three most stable geometries. Comparison with the geometry of the corresponding neutral and/or deprotonated nucleobases allow to point out the chemical bonds that are activated during the complexation process, and 
therefore likely to cleave during collisional activation. Note that bond lengths obtained with the G96LYP are slightly longer than for the B3LYP geometries. First, we can see that the interacting carbonyl groups are systematically lengthened while the non-interacting $\mathrm{CO}$ group is slightly shorten. If one looks at the $\mathbf{U 1 / d U 2}$ pair, the C4-O4 distance is increased by 0.052 $\AA$ while the $\mathrm{C} 2-\mathrm{O} 2$ is reduced by $0.034 \AA$ A. Studies of the topological properties of the electron density show that the electron density $\rho$ at the bcp always vary accordingly. Values of $\rho$ are summarized in Table 5 for the $\mathrm{Pb}^{2+} /$ uracil system. For example the values obtained at the $\mathrm{C} 4$ $\mathrm{O} 4 \mathrm{bcp}$ are $0.345,0.385$ and $0.409 \mathrm{e} . \mathrm{au}^{-3}$ for $\mathbf{U 1}, \mathbf{d U 2}$, and neutral uracil, respectively.

The N3-C4 bond also appears strongly activated in the case of structures $\mathbf{U} 2$ and $\mathbf{U 3}$ (T2 and T3, for thymine, Figure 6). This result is consistent with the data deduced from isotope labeling experiments. Perturbation theory energy analysis of "donor-acceptor" interactions in the NBO basis indicates that the N3-C4 elongation is mainly due to the increase of interaction between a $\mathrm{O} 4$ lone pair and the antibonding $\sigma^{*}{ }_{\mathrm{N} 3}{ }^{-} \mathrm{C} 4$ orbital.

MS/MS experiments (Table 1) clearly demonstrates that the loss of HNCO involves exclusively the elimination of the $\mathrm{C} 2$ and N3 atoms, and therefore should involve a structure in which $\mathrm{N} 3$ is not deprotonated, like $\mathbf{U 3}$. On the other hand the ion $\mathrm{m} / \mathrm{z} 250[\mathrm{~Pb}, \mathrm{~N}, \mathrm{C}, \mathrm{O}]^{+}$ exclusively includes N3, C2 and very likely $\mathrm{O} 2$ and could arise from a structure like U2, in which N3 is deprotonated. Consequently the N3-C4 bond cleavage promoted by the metallic center may constitute the first step of the mechanisms of dissociation. Starting from this assumption, we tried to explore the energetics associated with these two fragmentations and to our knowledge these calculations constitute some of the very first attempts to describe potential energy surfaces of metal-induced nucleobase ring-cleavages. The B3LYP/6$311+\mathrm{G}(3 \mathrm{df}, 2 \mathrm{p})$ dissociation pathways associated with elimination of isocyanic acid and formation of $\left[\mathrm{PbNCO}^{+}\right.$ions are given in Figure $7 \mathrm{a}$ and $7 \mathrm{~b}$, respectively. Searches for transition states were performed by first choosing a single parameter (either N1-C2 or N3-C4 
bond length) as the reaction coordinate and by varying the coordinate serially, all other parameters being allowed to optimize. Then, starting from the highest energy intermediate deduced from this scan calculation, a complete geometry optimization is performed. The resulting saddle points were confirmed by combination of IRC (forward and reverse) and frequency calculations (presence of a single negative eigenvalue). Transition states were very difficult to locate. The TS5 and TS6 are associated with cleavage of the bond N1-C2, as assessed by the corresponding negative eigenvalue. On the other hand, we failed to locate any saddle point associated with the N3-C4 bond cleavage, the energy increasing monotonously as the bond was elongated. However, note that the N1-C2 bond length also increases as the N3C4 is stretched.

Reverse IRC calculations from TS5 (TS6) do not tend towards the cyclic forms U3 (U2), but to acyclic forms. So, we tried to locate stable opened forms. This can be achieved provided the N3-C4 distance is frozen at a length deduced from IRC calculations. For both fragmentations, an opened species is found (Figure 7). These acyclic species open1 and open 2 in fact correspond to probable intermediates between the reactants and the TS along the reaction coordinate as they collapse toward $\mathbf{U} \mathbf{3}$ and $\mathbf{U} \mathbf{2}$, respectively, when optimization is carried out without any constraint.

The activation barriers TS5 and TS6 are high, lying about $230-235 \mathrm{~kJ} / \mathrm{mol}(2.4 \mathrm{eV})$ above the reactants. As mentioned before, distortion of the aromatic ring induced by a $\pi$-complexation already results in a structure lying $225 \mathrm{~kJ} \cdot \mathrm{mol}^{-1}$ above U1. Consequently, these high energy barriers are not sot surprising because the overall process corresponds to breakage of an aromatic ring. In addition, the fact that these two fragmentations already correspond to intense ions on CID spectra obtained at a center of mass collision energy of $1.2 \mathrm{eV}$, is consistent with experiments performed under a multiple collision regime. An other possible explanation is 
that the $[\mathrm{Pb} \text { (nucleobase) }-\mathrm{H}]^{+}$ions generated by Coulomb explosion of the doubly charged complexes should be energetic enough to pass the activation barriers.

Note that the mechanisms lead to acyclic fragments that can be described as ketenes bearing a cationized imino group (Figure 7a) . We have also considered the possible formation of both neutral or cationized cyclic fragments. But this corresponds to less favorable processes. For example, formation from $\mathbf{U} 2$ of a $[\mathrm{PbNCO}]^{+}$ion together with an unsaturated $\beta$ lactam, as displayed at the bottom of Figure 7, is more endothermic by $63 \mathrm{~kJ} \cdot \mathrm{mol}^{-1}$. Similarly, a $\mathrm{Pb}^{2+}-$ cationized 4-membered ring (Figure 7), which corresponds to the cyclic form of the acyclic complex shown in Figure $7 \mathrm{a}$, is $90 \mathrm{~kJ}^{\mathrm{mol}}{ }^{-1}$ less stable. Furthermore, the B3LYP/6$311+\mathrm{G}(3 \mathrm{df}, 2 \mathrm{p})$ calculations indicate that $\mathrm{H}-\mathrm{N}=\mathrm{C}=\mathrm{O}$ and $[\mathrm{PbNCO}]^{+}$species are 120 and 163 $\mathrm{kJ} . \mathrm{mol}^{-1}$ more stable than $\mathrm{HO}-\mathrm{C} \equiv \mathrm{N}$ and $[\mathrm{PbOCN}]^{+}$species, respectively.

Finally, MS/MS experiments were also performed on the first generation of fragment ions. As described in scheme 2 , the ion generated by elimination of isocyanic acid looses either $\mathrm{HCN}$ or $\mathrm{Pb}$, while the $[\mathrm{PbNCO}]^{+}$gives rise to $\mathrm{Pb}^{+}$ion $(\mathrm{m} / \mathrm{z} 208)$. Consequently, loss of carbon monoxide is not observed. This is in favor of the fragmentation processes described in Figure 7. Indeed, our calculations show that the $\mathrm{C} 4-\mathrm{C} 5$ bond is shortened as the pyrimidic ring is cleaved. If one considers for example the loss of $\mathrm{HNCO}$, The C4-C5 is $1.459 \AA$ in $\mathbf{U 3}$, and $1.349 \AA$ in the product ion. Similar trends are obtained for the formation of $[\mathrm{PbNCO}]^{+}$ion. This is therefore consistent with the fact that elimination of $\mathrm{CO}$ is not observed and that the $\mathrm{m} / \mathrm{z} 276$ ion (m/z 290 for thymine) doest not correspond to an acylium ion but instead can be described as a "ketene-like" species which can further rearrange to expel HCN. 


\section{Conclusion}

Positive-ion electrospray spectra show that lead(II) ions react with uracil and thymine to form both singly and doubly-charged species. Under MS/MS conditions, the $\left[\mathrm{Pb}(\text { nucleobase })_{\mathrm{m}}\right]^{2+}$ complexes $(m=6-12)$ easily dissociate either by loss of neutral ligand (the smallest doubly charged complex detected being $\left[\mathrm{Pb}(\text { nucleobase })_{2}\right]^{2+}$ ) or through coulombic explosion leading to $\left[\mathrm{Pb}(\text { nucleobase })_{\mathrm{n}}-\mathrm{H}\right]^{+}$ions. The most abundant complex, $[\mathrm{Pb}(\text { nucleobse })-\mathrm{H}]^{+}$has been extensively studied by MS/MS experiments. Results obtained with uracil and thymine are rigorously similar and show that this ion mainly dissociates by elimination of isocyanic acid, and by formation of a $[\mathrm{PbNCO}]^{+}$ion. According to labeling experiments, the $\mathrm{N} 3, \mathrm{C} 2$ and, very likely, $\mathrm{O} 2$ centers are exclusively expelled and complexed, respectively. Our experimental data suggest that the complex may correspond to a mixture of several structures. This is supported by the small difference in energy between the most stable minima. Furthermore, comparison with the geometry of deprotonated nucleobases reveals that lead cationization induces significant geometrical modifications, and more particularly the important activation of the N3-C4 bond, which accounts for the observed fragmentations. Potential energy surface associated with the two main dissociation channels are described.

\section{Acknowledgements}

The authors would like to thank the Institut du Développement et des Ressources en Informatique Scientifique (IDRIS, CNRS) for computational time. Pr. O. Mó and M. Yáñez are warmly acknowledged for helpful discussion. JYS would like to thank Denis Brasseur (Sanofi-Aventis) for kindly providing few milligrams of uracil-3- ${ }^{15} \mathrm{~N}$. AML would like to thank the COST action COST-STSM-D26-00321 for financial support. 


\section{Bibliography}

[1] R.A. Goyer, in: H.G. Seiler, H. Sigel, A. Sigel (Eds.), Handbook on toxicity of inorganic compounds, Dekker, New-York, 1988, p. 359.

[2] K. Gasiorowski, T. Pawlowski, J. Spychala, J. Swiatek, The Science of The Total Environment 64117.

[3] R.B. Martin, in: H.G. Seiler, H. Sigel, A. Sigel (Eds.), Handbook on toxicity of inorganic compounds., Dekker, New-York, 1988, p. 9.

[4] W.R. Farkas, Biochim. Biophys. Acta 155 (1968) 401.

[5] R.S. Brown, B.E. Hingerty, J.C. Dewan, A. Klug, Nature 303 (1983) 543.

[6] R.S. Brown, J.C. Dewan, A. Klug, Biochemistry 24 (1985) 4785.

[7] W.G. Scott, Curr. Opin. Chem. Biol. 3 (1999) 705.

[8] T. Pan, O.C. Uhlenbeck, Nature 358 (1992) 560.

[9] J.E. Wedekind, D.B. McKay, Nat Struct Biol 6 (1999) 261.

[10] J. Swiatek, B. Gulanowski, Acta Biochim. Pol. 37 (1990) 7.

[11] I. Smirnov, R.H. Shafer, J. Mol. Biol. 296 (2000) 1.

[12] C.P. Da Costa, H. Sigel, J. Biol. Inorg. Chem. 4 (1999) 508.

[13] C.P. Da Costa, H. Sigel, Inorg. Chem. 39 (2000) 5985.

[14] H. Sigel, C.P. Da Costa, R.B. Martin, Coord. Chem. Rev. 219 (2001) 435.

[15] P. Jayaweera, A.T. Blades, M.G. Ikonomou, P. Kebarle, J. Am. Chem. Soc. 112 (1990) 2452

[16] M.J. Frisch, G.W. Trucks, H.B. Schlegel, G.E. Scuseria, M.A. Robb, J.R. Cheeseman, V.G. Zakrzewski, J.A. Montgomery Jr, R.E. Stratmann, J.C. Burant, S. Dapprich, J.M. Millam, A.D. Daniels, K.N. Kudin, M.C. Strain, O. Farkas, J. Tomasi, V. Barone, M. Cossi, R. Cammi, B. Mennucci, C. Pomelli, C. Adamo, S. Clifford, J. Ochterski, G.A. Petersson, P.Y. Ayala, Q. Cui, K. Morokuma, D.K. Malick, A.D. Rabuck, K. 
Raghavachari, J.B. Foresman, J. Ciolowski, J.V. Ortiz, A.G. Baboul, B.B. Stefanov, G. Liu, A. Liashenko, P. Piskorz, I. Komaromi, R. Gomperts, R.L. Martin, D.J. Fox, T. Keith, M.A. Al-Laham, C.Y. Peng, A. Nanayakkara, C. Gonzalez, M. Challacombe, P.M.W. Gill, B. Johnson, W.S. Chen, M.W. Wong, J.L. Andres, M. Head-Gordon, E.S. Replogle, J.A. Pople, Gaussian 98, Revision A.7. Gaussian Inc., Pittsburgh PA, 1998.

[17] C. Lee, W. Yang, R. Parr, Phys. Rev. B Condens. Matter 37 (1988) 785.

[18] A.D. Becke, J. Chem. Phys. 98 (1993) 5648.

[19] P.M.W. Gill, Mol. Phys. 89 (1996) 433.

[20] C. Gonzalez, H.B. Schlegel, J. Chem. Phys. 90 (1989) 2154.

[21] W. Küchle, M. Dolg, H. Stoll, H. Preuss, Mol. Phys. 6 (1991) 1945.

[22] J.Y. Salpin, J. Tortajada, M. Alcamí, O. Mó, M. Yáñez, Chem. Phys. Lett. 383 (2004) 561.

[23] S. Hoyau, G. Ohanessian, Chem. Phys. Lett. 280 (1997) 266.

[24] P.R. Kemper, P. Weis, M.T. Bowers, P. Maitre, J. Am. Chem. Soc. 120 (1998) 13494.

[25] M. Alcamí, A. Luna, O. Mó, M. Yáñez, L. Boutreau, J. Tortajada, J. Phys. Chem. A 106 (2002) 2641

[26] L. González, O. Mó, M. Yáñez, J. Comput. Chem. 18 (1997) 1124.

[27] L. González, O. Mó, M. Yáñez, J. Chem. Phys. 109 (1998) 139.

[28] L. González, O. Mó, M. Yáñez, J. Phys. Chem. A 101 (1997) 9710.

[29] E.D. Glendening, A.E. Reed, F. Weinhold, NBO version 3.1.

[30] R.F.W. Bader, Atomes in molecules: A quantum theory. Clarendon Press, Oxford, 1990.

[31] T.J. Shi, G. Orlova, J.Z. Guo, D.K. Bohme, A.C. Hopkinson, K.W.M. Siu, J. Am. Chem. Soc. 126 (2004) 7975.

[32] S. Guillaumont, J. Tortajada, J.-Y. Salpin, under preparation. 
[33] C. Gutlé, T. Cartailler, J.-Y. Salpin, M.-P. Gaigeot, under preparation.

[34] CPMD. Copyright IMB Corp 1990-2004, Copyright MPI für Festkoerperforschung Stuttgart 1997-2001., 2003.

[35] B.A. Cerda, C. Wesdemiotis, J. Am. Chem. Soc. 118 (1996) 11884.

[36] J.V. Burda, J. Šponer, P. Hobza, J. Phys. Chem. 100 (1996) 7250.

[37] J.V. Burda, J. Šponer, J. Leszczynski, P. Hobza, J. Phys. Chem. B 101 (1997) 9670.

[38] J. Šponer, M. Sabat, J.V. Burda, J. Leszczynski, P. Hobza, J. Phys. Chem. B 103 (1999) 2528.

[39] J. Šponer, J.V. Burda, J. Leszczynski, P. Hobza, Journal of Biomolecular Structure \& Dynamics 17 (1999) 61.

[40] A. Famulari, F. Moroni, M. Sironi, E. Gianinetti, M. Raimondi, Journal Of Molecular Structure Theochem. Sep (2000) 209.

[41] M.T. Rodgers, P.B. Armentrout, J. Am. Chem. Soc. 122 (2000) 8548.

[42] J. Munoz, J. Šponer, P. Hobza, M. Orozco, F.J. Luque, J. Phys. Chem. B 105 (2001) 6051

[43] N. Russo, M. Toscano, A. Grand, J. Phys. Chem. B 105 (2001) 4735.

[44] J.D. Gu, J. Leszczynski, J. Phys. Chem. A 105 (2001) 10366.

[45] N. Russo, M. Toscano, A. Grand, J. Am. Chem. Soc. 123 (2001) 10272.

[46] N. Russo, E. Sicilia, M. Toscano, A. Grand, Int. J. Quant. Chem. 90 (2002) 903.

[47] N. Russo, M. Toscano, A. Grand, J. Phys. Chem. A 107 (2003) 11533.

[48] N. Russo, M. Toscano, A. Grand, J. Mass Spectrom. 38 (2003) 265.

[49] M.T. Rodgers, P.B. Armentrout, J. Am. Chem. Soc. 124 (2002) 2678.

[50] W.L. Zhu, X.M. Luo, C.M. Puah, X.J. Tan, J.H. Shen, J.D. Gu, K.X. Chen, H.L. Jiang, J. Phys. Chem. A 108 (2004) 4008.

[51] F. Moroni, A. Famulari, M. Raimondi, M. Sabat, J. Phys. Chem. B 107 (2003) 4196. 
[52] M. Noguera, J. Bertran, M. Sodupe, J. Phys. Chem. A 108 (2004) 333.

[53] Z. Yang, M.T. Rodgers, Int. J. Mass Spectrom. 241 (2005) 225.

[54] S. Guillaumont, J.-Y. Salpin, L. Rodríguez-Santiago, J. Tortajada, under preparation.

[55] A. Lamsabhi, J.-Y. Salpin, J. Tortajada, M. Yáñez, O. Mó, under preparation.

[56] H.C. Liu, J.L. Sun, Y.H. Hu, K.L. Han, S.H. Yang, Chem. Phys. Lett. 389 (2004) 342.

[57] C.C. Nelson, J.A. McCloskey, J. Am. Soc. Mass Spectrom. 5 (1994) 339.

[58] M. Piacenza, S. Grimme, J. Comput. Chem. 25 (2004) 83.

[59] E.S. Kryachko, M.T. Nguyen, T. Zeegers-Huyskens, J. Phys. Chem. A 105 (2001) 1288.

[60] S.X. Tian, C.F. Zhang, Z.J. Zhang, X.J. Chen, K.Z. Xu, Chem. Phys. 242 (1999) 217.

[61] J.K. Wolken, F. Tureček, J. Am. Soc. Mass Spectrom. 11 (2000) 1065.

[62] S. Rochut, C. Pepe, J.P. Paumard, J.C. Tabet, Rapid Commun. Mass Spectrom. 18 (2004) 1686.

[63] T. Marino, M. Toscano, N. Russo, A. Grand, Int. J. Quant. Chem. 98 (2004) 347.

[64] A.M. Lamsabhi, M. Alcamí, O. Mó, M. Yáñez, ChemPhysChem 4 (2003) 1011.

[65] J.-Y. Salpin, S. Guillaumont, J. Tortajada, under preparation.

[66] M.T. Nguyen, A.K. Chandra, T. Zeegers-Huyskens, J. Chem. Soc. Faraday Trans. 94 (1998) 1277.

[67] A.K. Chandra, M.T. Nguyen, T. Uchimaru, T. Zeegers-Huyskens, J. Phys. Chem. A 103 (1999) 8853.

[68] M.A. Kurinovich, J.K. Lee, J. Am. Chem. Soc. 122 (2000) 6258.

[69] M.A. Kurinovich, J.K. Lee, J. Am. Soc. Mass Spectrom. 13 (2002) 985.

[70] Y.Q. Huang, H. Kenttamaa, J. Phys. Chem. A 107 (2003) 4893.

[71] T.M. Miller, S.T. Arnold, A.A. Viggiano, A.E.S. Miller, Journal Of Physical Chemistry A. Apr 108 (2004) 3439.

[72] K.C. Chang, E. Grundwald, J. Am. Chem. Soc. 98 (1976) 3737. 
[73] O. Bensaude, J. Aubard, M. Dreyfus, G. Dodin, J.E. Dubois, J. Am. Chem. Soc. 100 (1978) 2823.

[74] B. Lippert, J. Raman Spectrosc. 8 (1979) 274.

[75] A.M. Fiskin, M. Beer, Biochemistry 4 (1965) 1289.

[76] G. Lauer, W. Schäfer, A. Schweig, Tetrahedr. Lett. 16 (1975) 3939.

[77] A. Padva, T.J. O'Donnell, P.R. Lebreton, Chem. Phys. Lett. 41 (1976) 278.

[78] H. Ruterjans, E. Kaun, W.E. Hull, H.H. Limbach, Nucleic Acids Res 10 (1982) 7027.

[79] M. Szczesniak, M.J. Nowak, H. Rostkowska, K. Szczepaniak, W.B. Person, D. Shugar, J. Am. Chem. Soc. 105 (1983) 5969.

[80] D. Dougherty, K. Wittel, J. Meeks, S.P. McGlynn, J. Am. Chem. Soc. 98 (1984) 3815.

[81] M. Fujii, T. Tamura, N. Mikami, M. Ito, Chem. Phys. Lett. 126 (1986) 583.

[82] Y. Tsuchiya, T. Tamura, M. Fujii, M. Ito, J. Phys. Chem. 92 (1988) 1760.

[83] B.B. Brady, L.A. Peteanu, D.H. Levy, Chem. Phys. Lett. 147 (1988) 538.

[84] M. Kubota, T. Kobayashi, J. Electron Spectroscopy Relat. Phenom. 82 (1996) 61.

[85] S. Morpurgo, M. Bossa, G.O. Morpurgo, Chem. Phys. Lett. 280 (1997) 233.

[86] L. Gorb, Y. Podolyan, J. Leszczynski, J. Mol. Struct. Theochem 487 (1999) 47.

[87] M. Lamsabhi, M. Alcamí, O. Mó, W. Bouab, M. Esseffar, J.L.M. Abboud, M. Yáñez, J. Phys. Chem. A 104 (2000) 5122.

[88] M. Peschke, A.T. Blades, P. Kebarle, J. Am. Chem. Soc. 122 (2000) 10440.

[89] I. Corral, O. Mó, M. Yáñez, J.Y. Salpin, J. Tortajada, L. Radom, J. Phys. Chem. A 108 (2004) 10080.

[90] L. Shimoni-Livny, J.P. Glusker, W. Bock, Inorg. Chem. 37 (1998) 1853.

[91] J.Y. Salpin, J. Tortajada, J. Phys. Chem. A 107 (2003) 2943. 


\section{Table and Figure caption}

TABLE 1 : Summary of MS/MS spectra obtained with labeled uracil and thymine (loss of label is indicated in bold).

TABLE 2: Total (Hartree), ZPE $\left(\mathrm{kJ}^{\mathrm{m}} \mathrm{mol}^{-1}\right)$ and relative energies $\left(\mathrm{kJ} \cdot \mathrm{mol}^{-1}\right)$ of the different $[\mathrm{Pb}(\text { uracil })-\mathrm{H}]^{+}$structures

TABLE 3: Total (Hartree), ZPE $\left(\mathrm{kJ}^{\mathrm{m}} \mathrm{mol}^{-1}\right)$ and relative energies $\left(\mathrm{kJ} \cdot \mathrm{mol}^{-1}\right)$ of the different $[\mathrm{Pb}$ (thymine $)-\mathrm{H}]^{+}$structures

TABLE 4: Summary of natural charges (e-) obtained at the B3LYP/6-31G(d,p) level (the C7 center is the carbon of the methyl group for thymine).

TABLE 5: B3LYP/6-31G(d,p) values of the electron density $\rho\left(\mathrm{e} . \mathrm{au}^{-3}\right)$ at the bond critical points deduced from the AIM topological study of structures involving uracil..

Figure 1. Positive-ion electrospray mass spectra of a a) $5 \times 10^{-5} \mathrm{~mol} \cdot \mathrm{L}^{-1} / 10^{-4} \mathrm{~mol} \cdot \mathrm{L}^{-1}$ and b) $10^{-}$ ${ }^{3}$ mol. $\mathrm{L}^{-1} / 10^{-3}$ mol. $\mathrm{L}^{-1} \mathrm{~Pb}\left(\mathrm{NO}_{3}\right)_{2} /$ thymine aqueous solution.

Figure 2. Low-energy CID spectra of $\left[\mathrm{Pb}(\text { uracil) - } \mathrm{H}]^{+}\right.$ions, with : a) uracil, b) $3-{ }^{15} \mathrm{~N}$-uracil, c) $2-{ }^{13} \mathrm{C}$-uracil and d) $2-{ }^{13} \mathrm{C}-1,3-{ }^{15} \mathrm{~N}_{2}$-uracil.

Figure 3. Summary of the global minima found for the $[\mathrm{Pb}(\mathrm{U})-\mathrm{H}]^{+}$ion. The nomenclature adopted is the same for uracil and thymine.

Figure 4. B3LYP/6-311+G(3df,2p) and B3LYP/6-31G(d,p) (in italic) energies $\left(\mathrm{kJ}^{\mathrm{m}} \mathrm{mol}{ }^{-1}\right)$ of several tautomerization processes occurring for a) deprotonated and b) cationized uracil.

Figure 5. B3LYP/6-31G(d,p) and G96LYP/6-31G(d,p) geometries of the lowest energy structures of neutral, deprotonated uracil, and $[\mathrm{Pb}(\mathrm{U})-\mathrm{H}]^{+}$complexes (bond lengths are given in Angströms. The G96LYP distances are in italic). 
Figure 6. B3LYP/6-31G(d,p) and G96LYP/6-31G(d,p) geometries of the lowest energy structures of neutral, deprotonated thymine, and $[\mathrm{Pb}(\mathrm{T})-\mathrm{H}]^{+}$complexes (bond lengths are given in Angströms. The distances obtained with the G96LYP functional are in italic).

Figure 7. $B 3 L Y P / 6-311+G(3 d f, 2 p)+Z P E$ potential energy surfaces associated with a) elimination of $\mathrm{HNCO}$ and $\mathbf{b})$ formation of $[\mathrm{PbNCO}]^{+}$from the $[\mathrm{Pb}(\mathrm{U})-\mathrm{H}]^{+}$complex (relative energies are given $\mathrm{kJ} \mathrm{mol}^{-1}$ and bond lengths are given in Angströms). See text for details. 
TABLE 1 : Summary of MS/MS spectra obtained with labeled uracil and thymine (loss of label is indicated in bold).

\begin{tabular}{|c|c|c|c|c|c|}
\hline \multirow{2}{*}{\multicolumn{2}{|c|}{$\begin{array}{c}\text { Precursor ion } \\
[\mathrm{Pb} \text { (nucleobase })-\mathrm{H}]^{+}\end{array}$}} & \multicolumn{4}{|c|}{ Product ions $(\mathrm{m} / \mathrm{z})$} \\
\hline & & \multirow[t]{2}{*}{-HNCO } & \multirow{2}{*}{$\begin{array}{l}-\mathrm{C}_{3} \mathrm{H}_{3} \mathrm{NO}^{\mathrm{a}} \\
\text { uracil }\end{array}$} & \multirow[t]{2}{*}{$-\mathrm{HNCO} /-\mathrm{HCN}$} & \multirow[t]{2}{*}{$-\mathrm{HNCO} /-\mathrm{Pb}$} \\
\hline & & & & & \\
\hline not labeled & $\mathrm{m} / \mathrm{z} 319$ & 276 & 250 & 249 & 68 \\
\hline $2-{ }^{13} \mathrm{C}$ & $\mathrm{m} / \mathrm{z} 320$ & 276 & 251 & 249 & 68 \\
\hline $3-{ }^{15} \mathrm{~N}$ & $\mathrm{~m} / \mathrm{z} 320$ & 276 & 251 & 249 & 68 \\
\hline $2-{ }^{13} \mathrm{C}-1,3-{ }^{15} \mathrm{~N}_{2}$ & $\mathrm{~m} / \mathrm{z} 322$ & 277 & 252 & 249 & 69 \\
\hline & & & thymine & & \\
\hline not labeled & $\mathrm{m} / \mathrm{z} 333$ & 290 & 250 & 263 & 82 \\
\hline $2-{ }^{13} \mathrm{C}$ & $\mathrm{m} / \mathrm{z} 334$ & 290 & 251 & 263 & 82 \\
\hline $3-{ }^{15} \mathrm{~N}$ & $\mathrm{~m} / \mathrm{z} 334$ & 290 & 251 & 263 & 82 \\
\hline
\end{tabular}

${ }^{\mathrm{a}}-\mathrm{C}_{4} \mathrm{H}_{5} \mathrm{NO}$ for thymine 
TABLE 2: Total (Hartree), ZPE $\left(\mathrm{kJ}^{\mathrm{m}} \mathrm{mol}^{-1}\right)$ and relative energies $\left(\mathrm{kJ} \cdot \mathrm{mol}^{-1}\right)$ of the different $[\mathrm{Pb}(\text { uracil })-\mathrm{H}]^{+}$structures

\begin{tabular}{cccccccc}
\hline \multirow{2}{*}{ Structure } & \multicolumn{2}{c}{ B3LYP/6-311+G(3df,2p) } & & \multicolumn{2}{c}{ G96LYP/6-311+G(3df,2p) } \\
\cline { 2 - 3 } \cline { 7 - 8 } & $\mathrm{E}$ & ZPVE $^{\mathrm{a}}$ & $\Delta \mathrm{E}+\Delta$ ZPVE & & $\mathrm{E}$ & ZPVE $^{\mathrm{a}}$ & $\Delta \mathrm{E}+\Delta \mathrm{ZPVE}$ \\
\hline U1 & -417.597596 & 199.84 & 0.0 & & -417.478671 & 192.82 & 0.0 \\
U2 & -417.589651 & 199.25 & 20.3 & & -417.470038 & 192.14 & 22.0 \\
U3 & -417.585689 & 198.82 & 30.2 & & -417.467257 & 191.59 & 28.7 \\
U4t & -417.585936 & 199.44 & 30.2 & & -417.466539 & 192.39 & 31.4 \\
U5t & -417.584262 & 199.33 & 34.5 & & -417.464323 & 192.34 & 37.2 \\
U6t & -417.578273 & 198.81 & 49.7 & & -417.459252 & 191.79 & 50.0 \\
U7t & -417.576832 & 198.34 & 53.0 & & -417.457147 & 191.37 & 55.1 \\
U8t & -417.569548 & 197.91 & 71.7 & & -417.450524 & 191.79 & 72.9 \\
U9t & -417.568548 & 197.77 & 74.2 & & -417.449596 & 190.96 & 74.5 \\
U10t & -417.521975 & 194.30 & 193.0 & & -417.408484 & 186.72 & 178.2 \\
U11t & -417.526329 & 194.45 & 181.7 & & -417.409778 & 186.78 & 174.8 \\
U12 & -417.572786 & 201.39 & 66.7 & & -417.454561 & 194.21 & 64.7 \\
\hline
\end{tabular}

${ }^{\text {a }}$ Obtained with the 6-31G(d,p) basis set. 
TABLE 3: Total (Hartree), ZPE $\left(\mathrm{kJ}^{\mathrm{m}} \mathrm{mol}^{-1}\right)$ and relative energies $\left(\mathrm{kJ} \cdot \mathrm{mol}^{-1}\right)$ of the different $[\mathrm{Pb}$ (thymine $)-\mathrm{H}]^{+}$structures

\begin{tabular}{cccccccc}
\hline \multirow{2}{*}{ Structure } & \multicolumn{2}{c}{$\mathrm{B} 3 \mathrm{LYP} / 6-311+\mathrm{G}(3 \mathrm{df}, 2 \mathrm{p})$} & & \multicolumn{2}{c}{$\mathrm{G} 96 \mathrm{LYP} / 6-311+\mathrm{G}(3 \mathrm{df}, 2 \mathrm{p})$} \\
\cline { 2 - 3 } \cline { 7 - 8 } & $\mathrm{E}$ & ZPVE $^{\mathrm{a}}$ & $\Delta \mathrm{E}+\Delta \mathrm{ZPVE}$ & & $\mathrm{E}$ & ZPVE $^{\mathrm{a}}$ & $\Delta \mathrm{E}+\Delta \mathrm{ZPVE}$ \\
\hline $\mathrm{T} 1$ & -456.930859 & 272.41 & 0.0 & & -456.782205 & 263.53 & 0.0 \\
T2 & -456.925188 & 272.14 & 14.6 & & -456.775607 & 263.12 & 16.9 \\
T3 & -456.921007 & 271.62 & 25.1 & & -456.772508 & 262.42 & 24.3 \\
T4t & -456.919826 & 272.19 & 28.7 & & -456.770488 & 263.25 & 30.5 \\
T5t & -456.917991 & 271.64 & 33.0 & & -456.768348 & 262.78 & 35.6 \\
T6t & -456.911514 & 271.46 & 49.8 & & -456.762456 & 262.58 & 50.9 \\
T7t & -456.909968 & 270.84 & 53.3 & & -456.760424 & 262.00 & 55.7 \\
T8t & -456.903109 & 270.52 & 71.0 & & -456.754290 & 261.65 & 71.4 \\
T9t & -456.902291 & 270.26 & 72.9 & & -456.753690 & 261.48 & 72.8 \\
T10t & -456.860607 & 266.22 & 178.3 & & -456.715806 & 256.77 & 167.6 \\
T11t & -456.862871 & 267.22 & 173.3 & & -456.716354 & 257.62 & 167.0 \\
\hline
\end{tabular}

${ }^{\text {a }}$ Obtained with the 6-31G(d,p) basis set. 
TABLE 4: Summary of natural charges (e-) obtained at the B3LYP/6-31G(d,p) level (the C7 center is the carbon of the methyl group for thymine).

\begin{tabular}{|c|c|c|c|c|c|c|}
\hline \multirow[t]{2}{*}{ Atom } & \multicolumn{6}{|c|}{ Natural charges } \\
\hline & U1 & $\mathbf{U} 2$ & $\mathbf{U 3}$ & dU1 & dU2 & neutral \\
\hline N1 & -0.61 & -0.60 & -0.83 & -0.61 & -0.67 & -0.64 \\
\hline $\mathrm{C} 2$ & 0.83 & 0.83 & 0.83 & 0.73 & 0.77 & 0.82 \\
\hline $\mathrm{O} 2$ & -0.57 & -0.77 & -0.79 & -0.68 & -0.73 & -0.62 \\
\hline N3 & -0.86 & -0.87 & -0.64 & -0.67 & -0.68 & -0.69 \\
\hline $\mathrm{C} 4$ & 0.66 & 0.66 & 0.66 & 0.58 & 0.60 & 0.65 \\
\hline $\mathrm{O} 4$ & -0.76 & -0.53 & 0.79 & -0.68 & -0.70 & -0.58 \\
\hline $\mathrm{C} 5$ & -0.40 & -0.35 & -0.36 & -0.48 & -0.41 & -0.40 \\
\hline C6 & 0.12 & 0.02 & 0.03 & 0.01 & -0.02 & 0.029 \\
\hline \multirow[t]{2}{*}{$\mathrm{Pb}$} & 1.55 & 1.56 & 1.55 & - & - & - \\
\hline & $\mathbf{T 1}$ & $\mathbf{T} 2$ & $\mathbf{T 3}$ & dT1 & dT2 & neutral \\
\hline N1 & -0.61 & -0.59 & -0.82 & -0.64 & -0.67 & -0.64 \\
\hline $\mathrm{C} 2$ & 0.83 & 0.83 & 0.83 & 0.78 & 0.77 & 0.82 \\
\hline $\mathrm{O} 2$ & -0.57 & -0.78 & -0.79 & 0.71 & -0.73 & -0.62 \\
\hline N3 & -0.86 & -0.87 & 0.63 & -0.69 & -0.68 & -0.68 \\
\hline $\mathrm{C} 4$ & 0.67 & 0.67 & 0.67 & 0.63 & 0.61 & 0.66 \\
\hline $\mathrm{O} 4$ & -0.77 & -0.55 & -0.52 & -0.28 & -0.70 & -0.59 \\
\hline $\mathrm{C} 5$ & -0.18 & -0.12 & -0.14 & -0.28 & -0.19 & -0.18 \\
\hline C6 & 0.12 & 0.01 & 0.02 & 0.04 & -0.01 & 0.02 \\
\hline C7 & -0.70 & -0.71 & -0.71 & -0.68 & -0.68 & -0.70 \\
\hline $\mathrm{Pb}$ & 1.53 & 1.55 & 1.54 & - & - & - \\
\hline
\end{tabular}


TABLE 5: B3LYP/6-31G(d,p) values of the electron density $\rho\left(\mathrm{e} . \mathrm{au}^{-3}\right)$ at the bond critical point deduced from the AIM topological study of structures involving uracil.

\begin{tabular}{ccccccc}
\hline \multirow{2}{*}{ Bond } & \multicolumn{7}{c}{$\rho$} \\
\cline { 2 - 7 } & U1 & U2 & U3 & dU1 & dU2 & neutral \\
\hline N1-C2 & 0.294 & 0.340 & 0.342 & 0.334 & 0.272 & 0.307 \\
C2-N3 & 0.310 & 0.346 & 0.349 & 0.290 & 0.349 & 0.315 \\
C2-O2 & 0.417 & 0.358 & 0.350 & 0.395 & 0.391 & 0.414 \\
N3-C4 & 0.329 & 0.283 & 0.264 & 0.298 & 0.325 & 0.289 \\
C4-O4 & 0.345 & 0.411 & 0.416 & 0.388 & 0.385 & 0.409 \\
C4-C5 & 0.307 & 0.279 & 0.284 & 0.295 & 0.269 & 0.284 \\
C5-C6 & 0.325 & 0.340 & 0.337 & 0.317 & 0.337 & 0.337 \\
C6-N1 & 0.322 & 0.289 & 0.299 & 0.345 & 0.315 & 0.308 \\
\hline
\end{tabular}



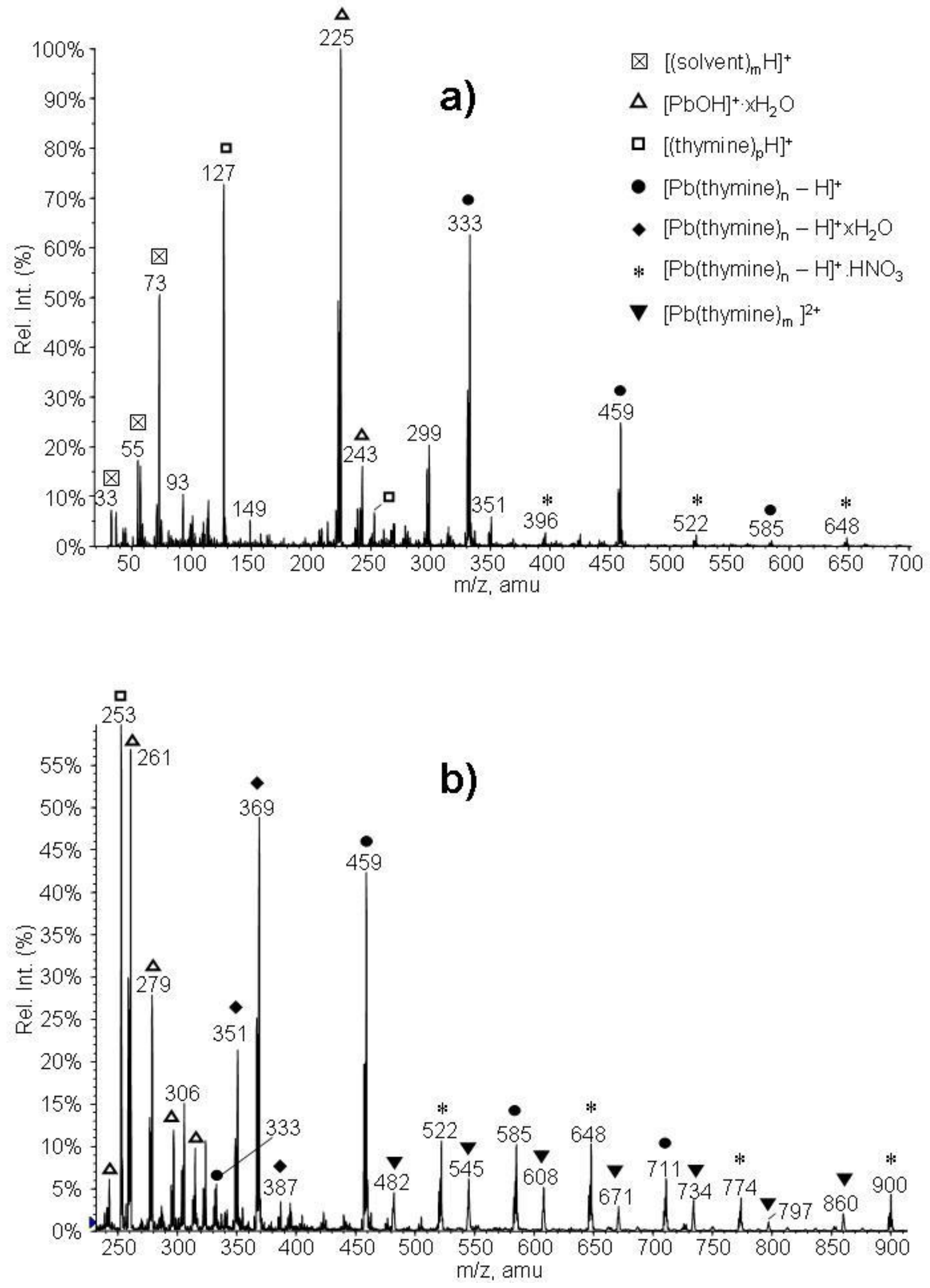

Figure 1 

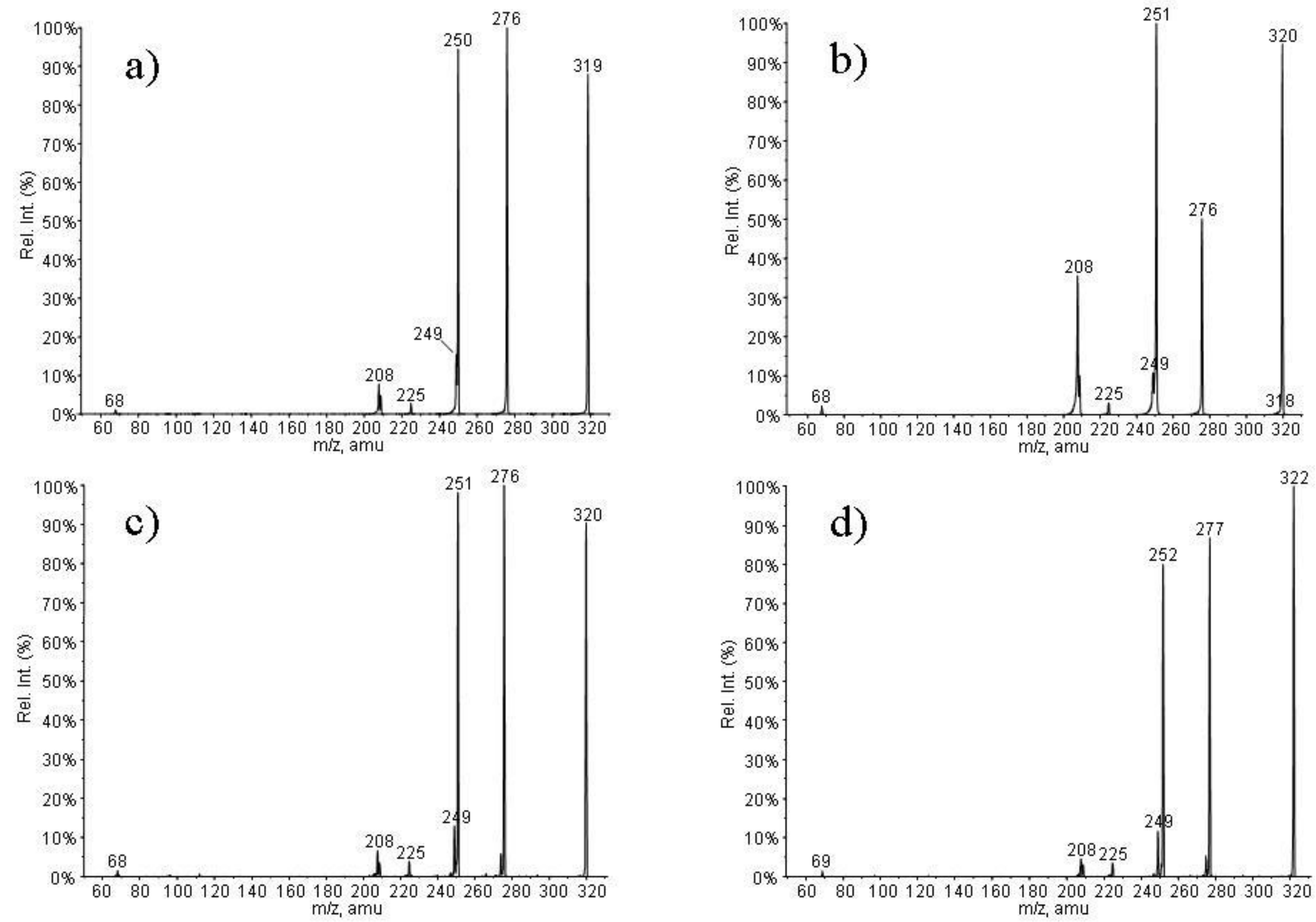

Figure 2 


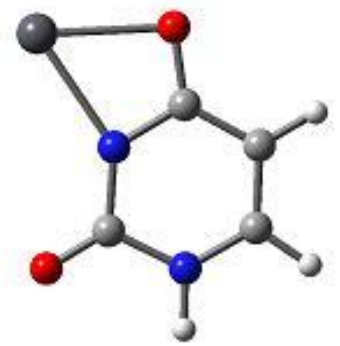

U1

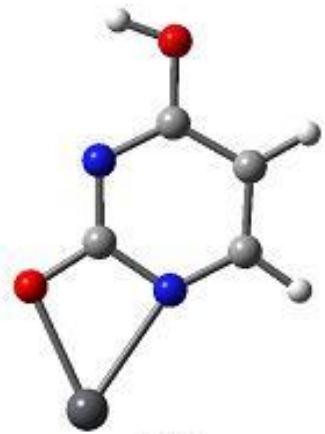

U $4 t$

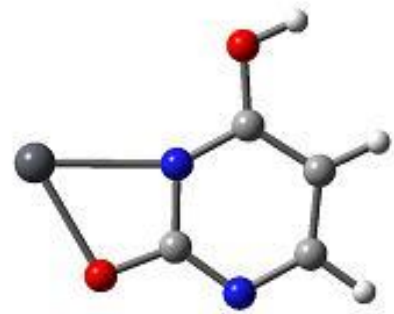

U7t

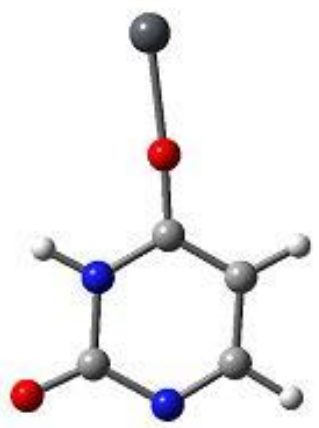

U 10t

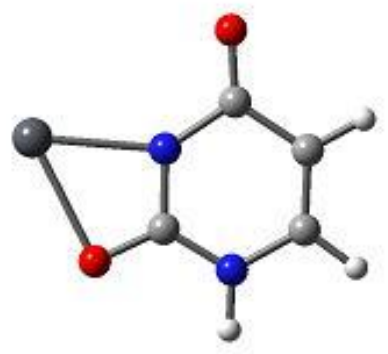

U2

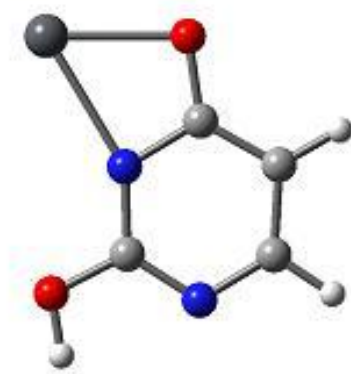

U5t

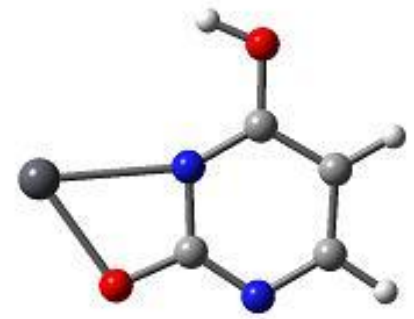

U8t

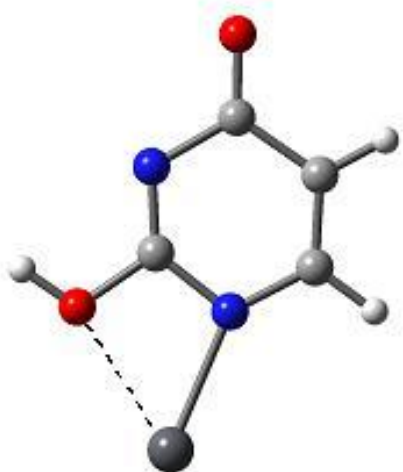

U11t

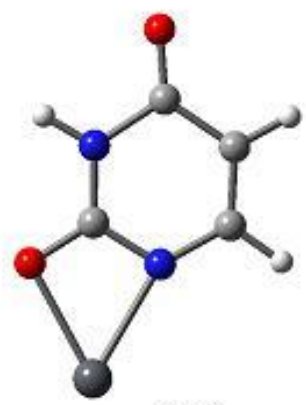

U3

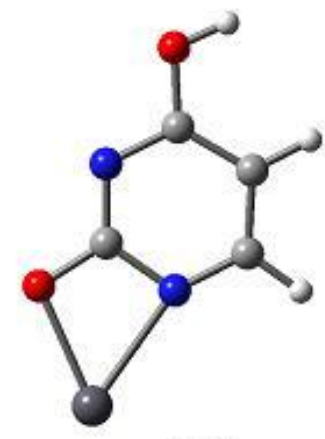

U6t

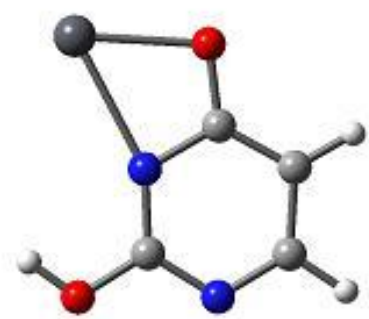

U9t

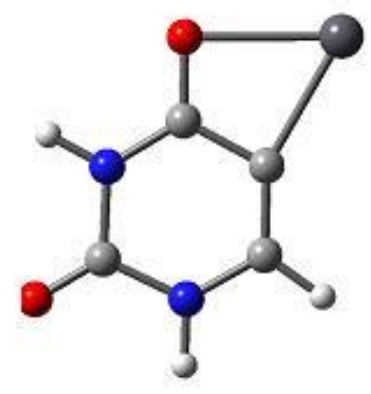

U 12

Figure 3 

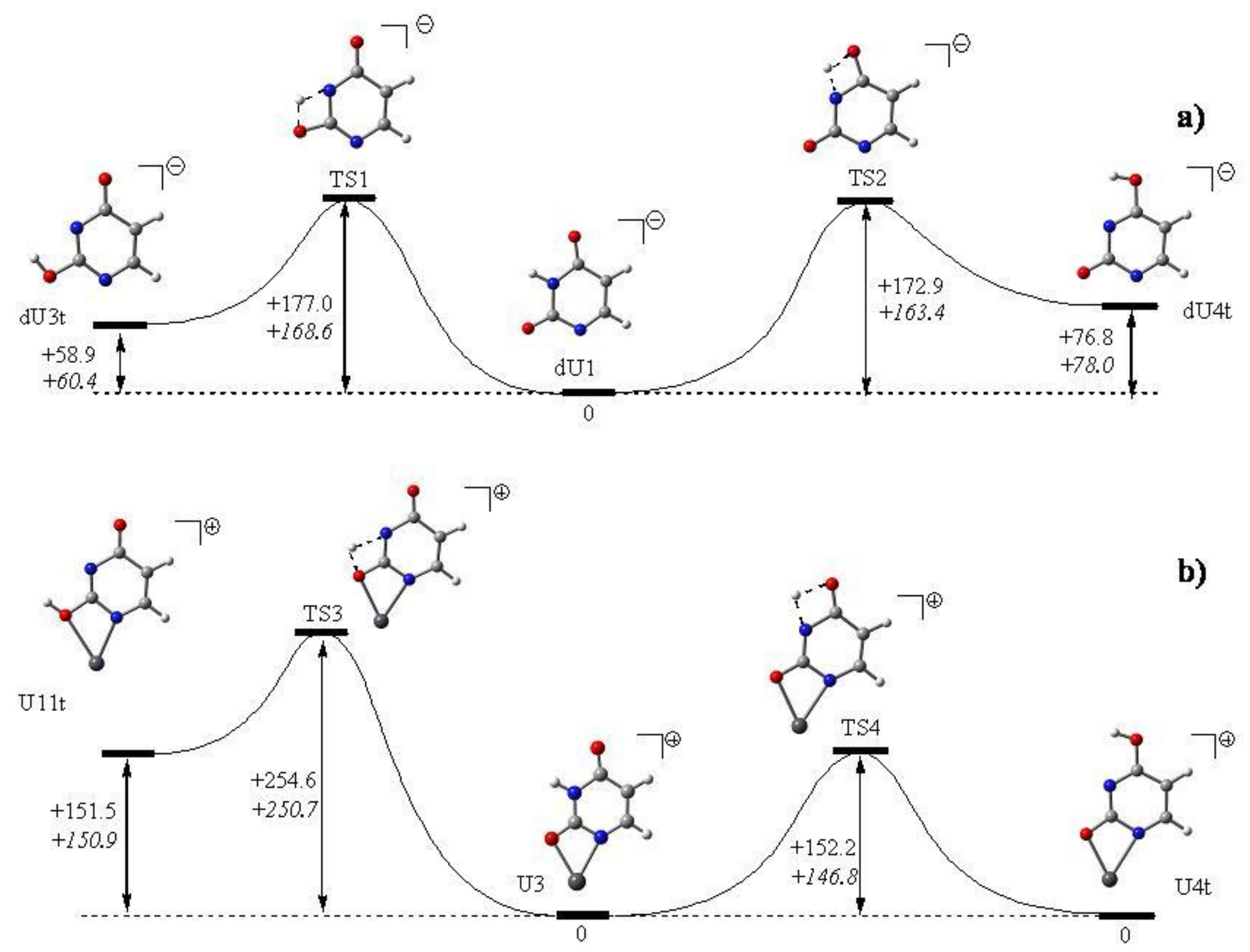

Figure 4 

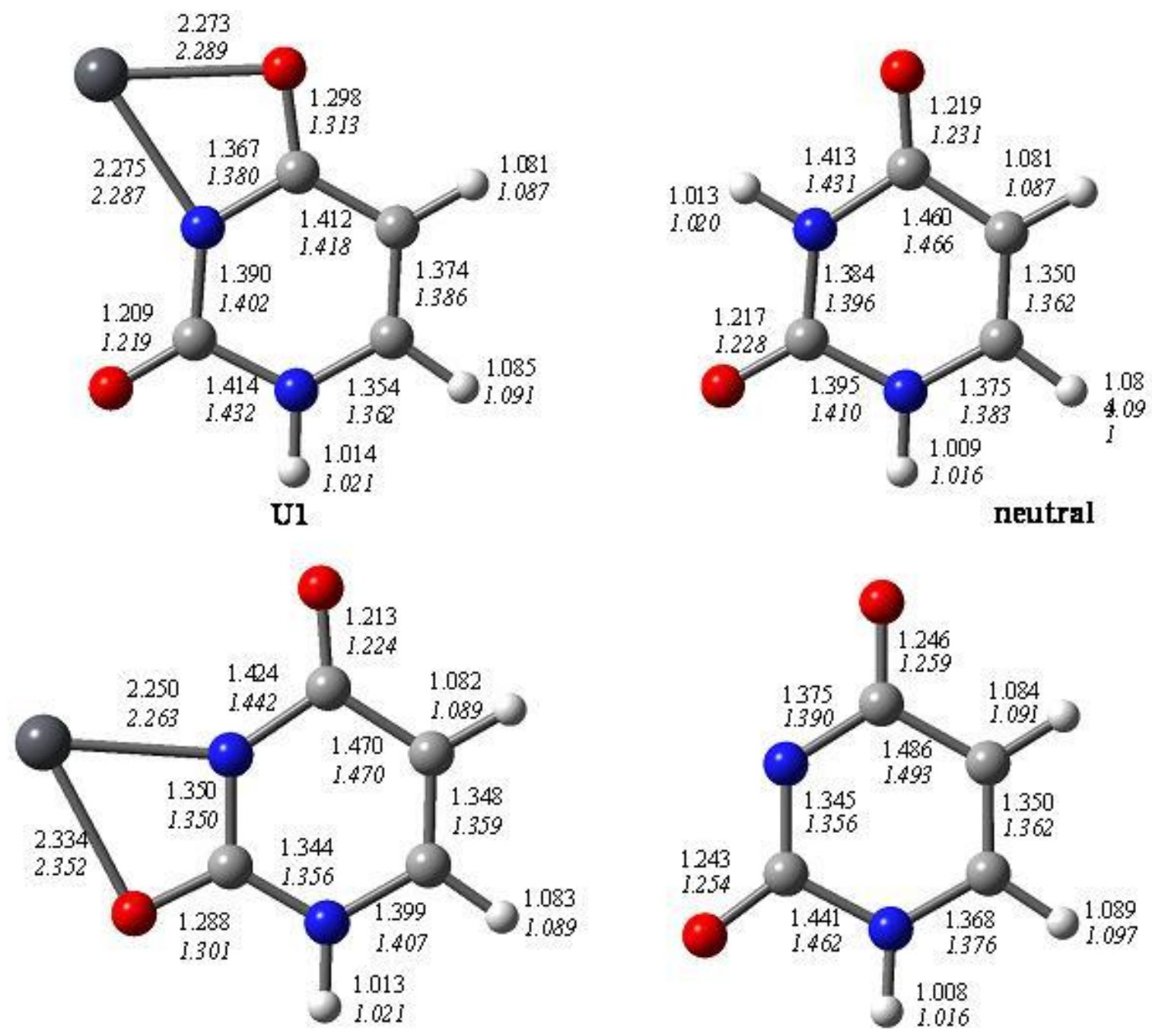

U2

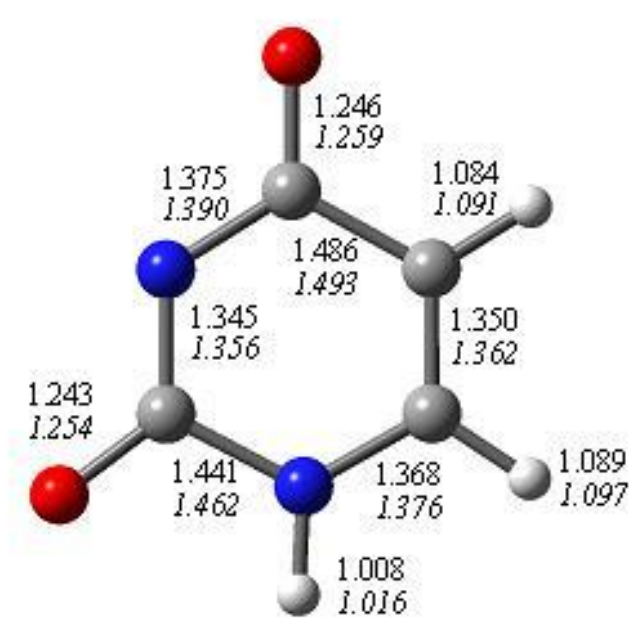

dU2
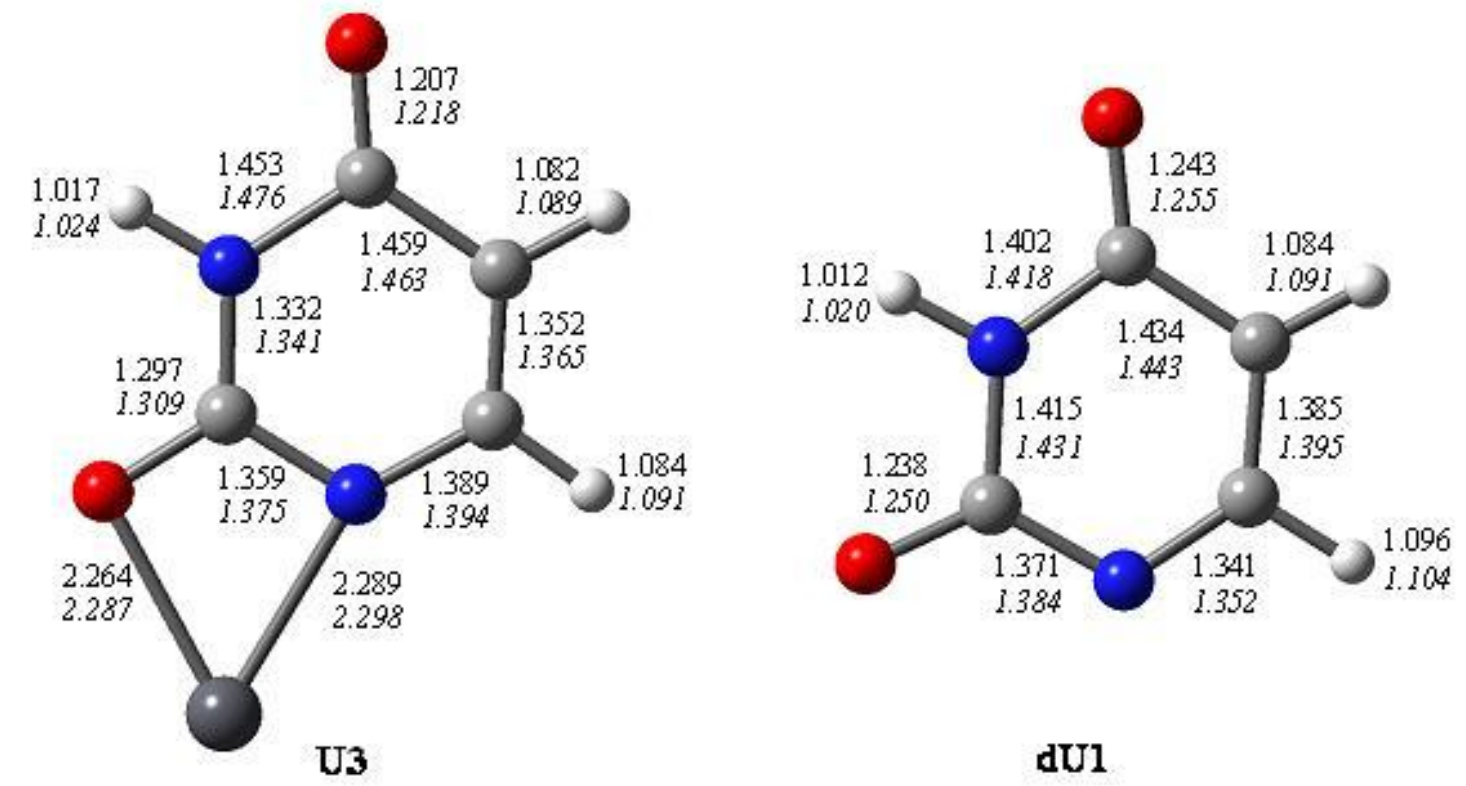

Figure 5 


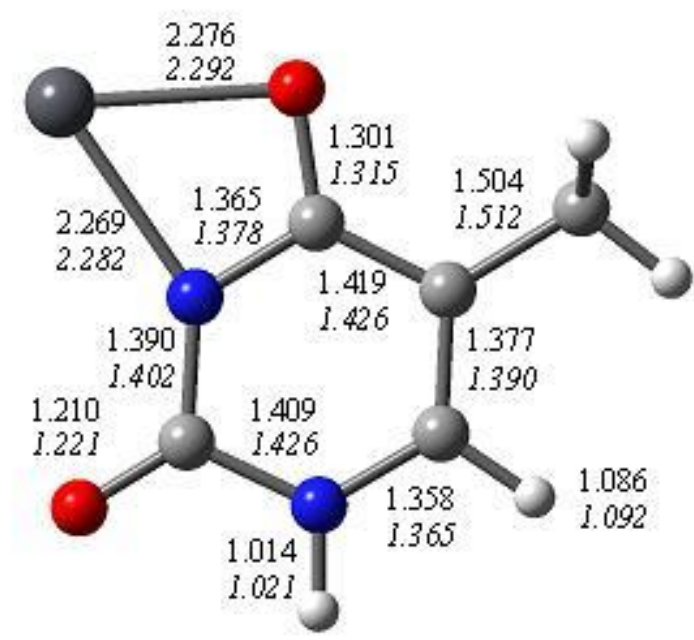

T1

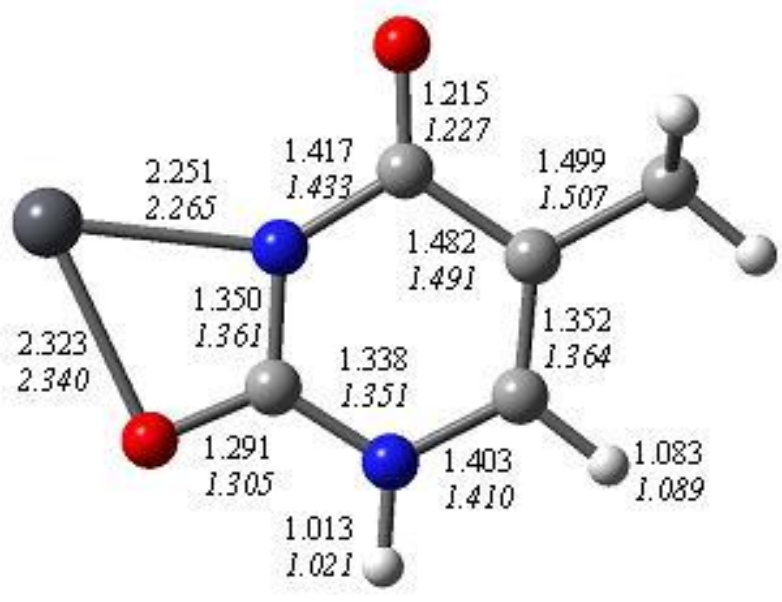

T2

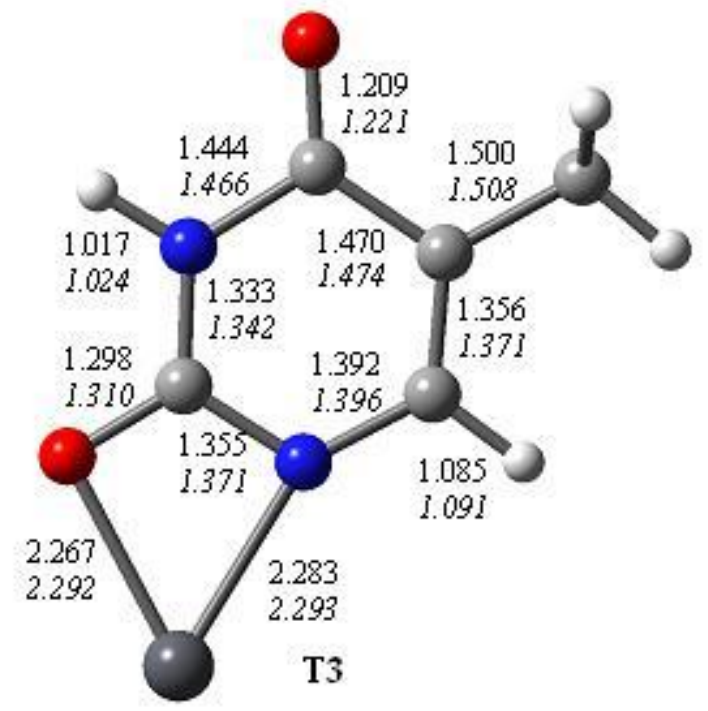

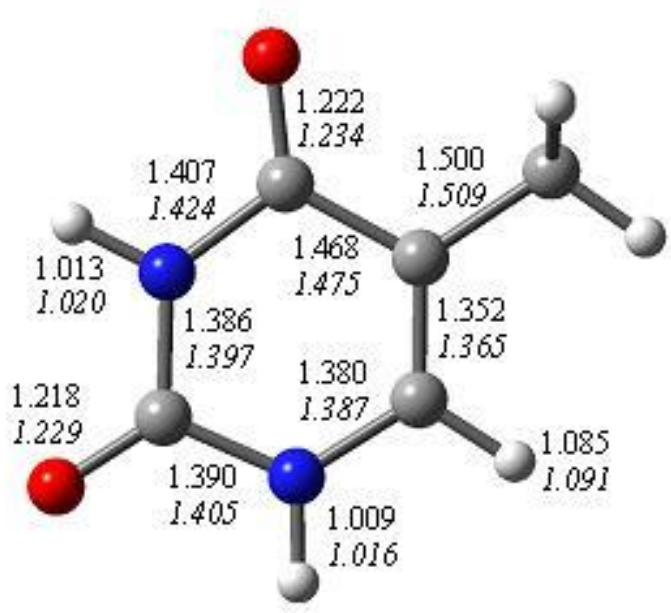

Neutral

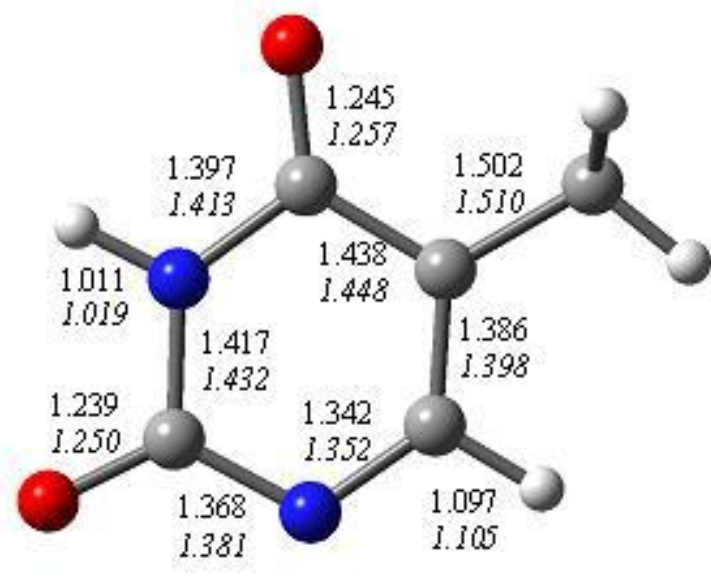

dT1

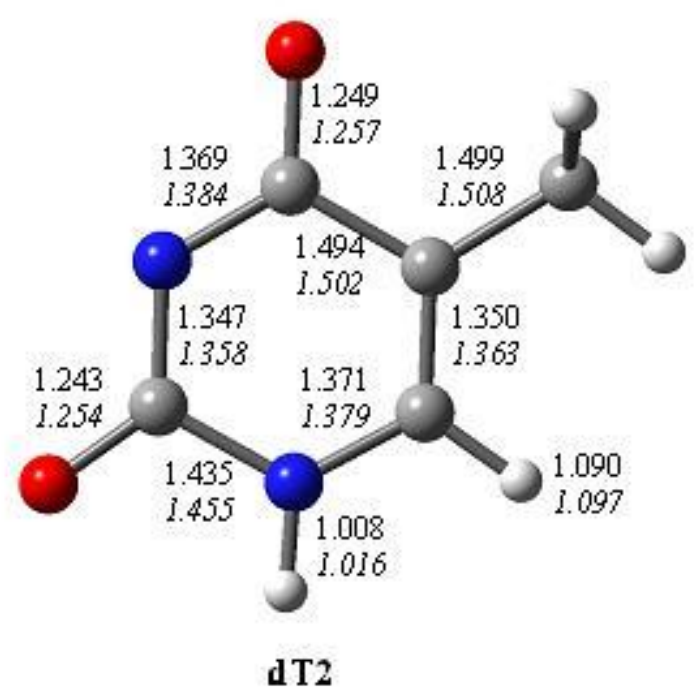

Figure 6 


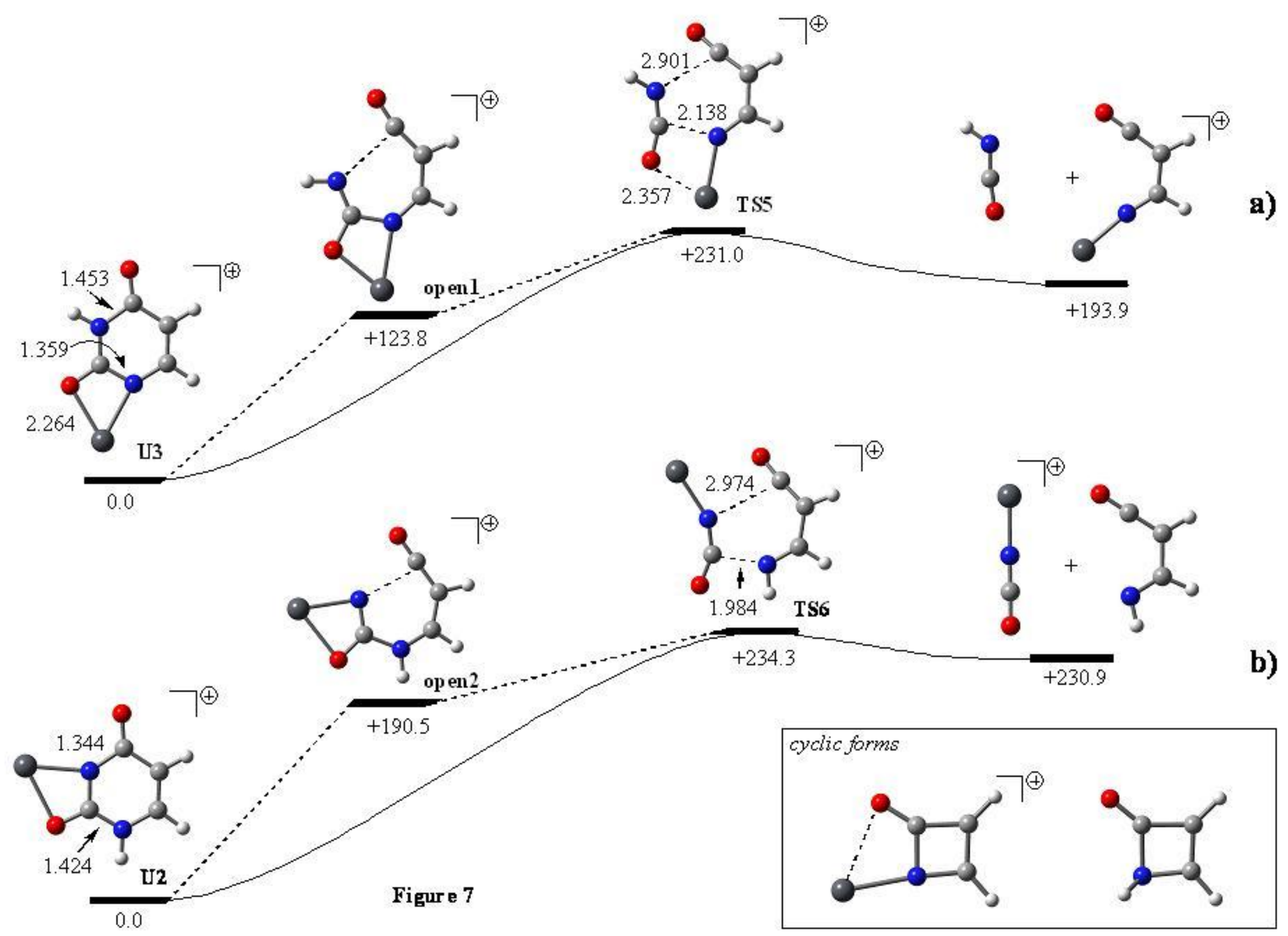




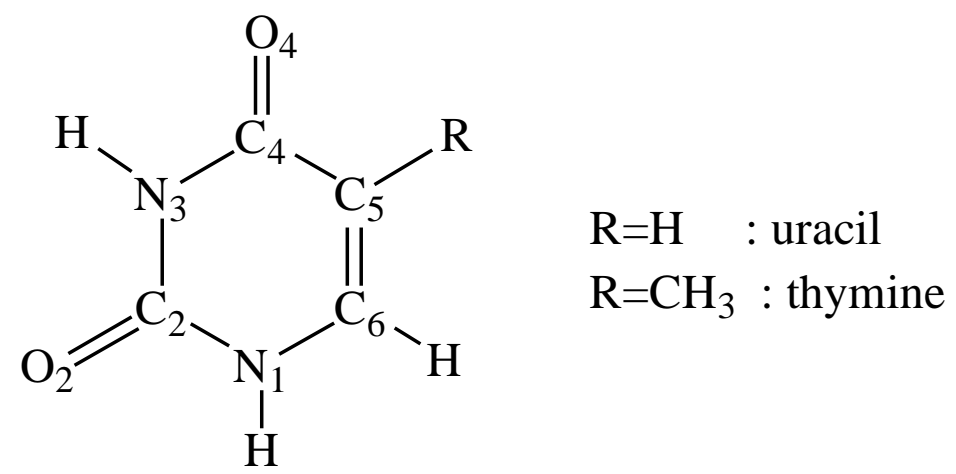

Scheme 1

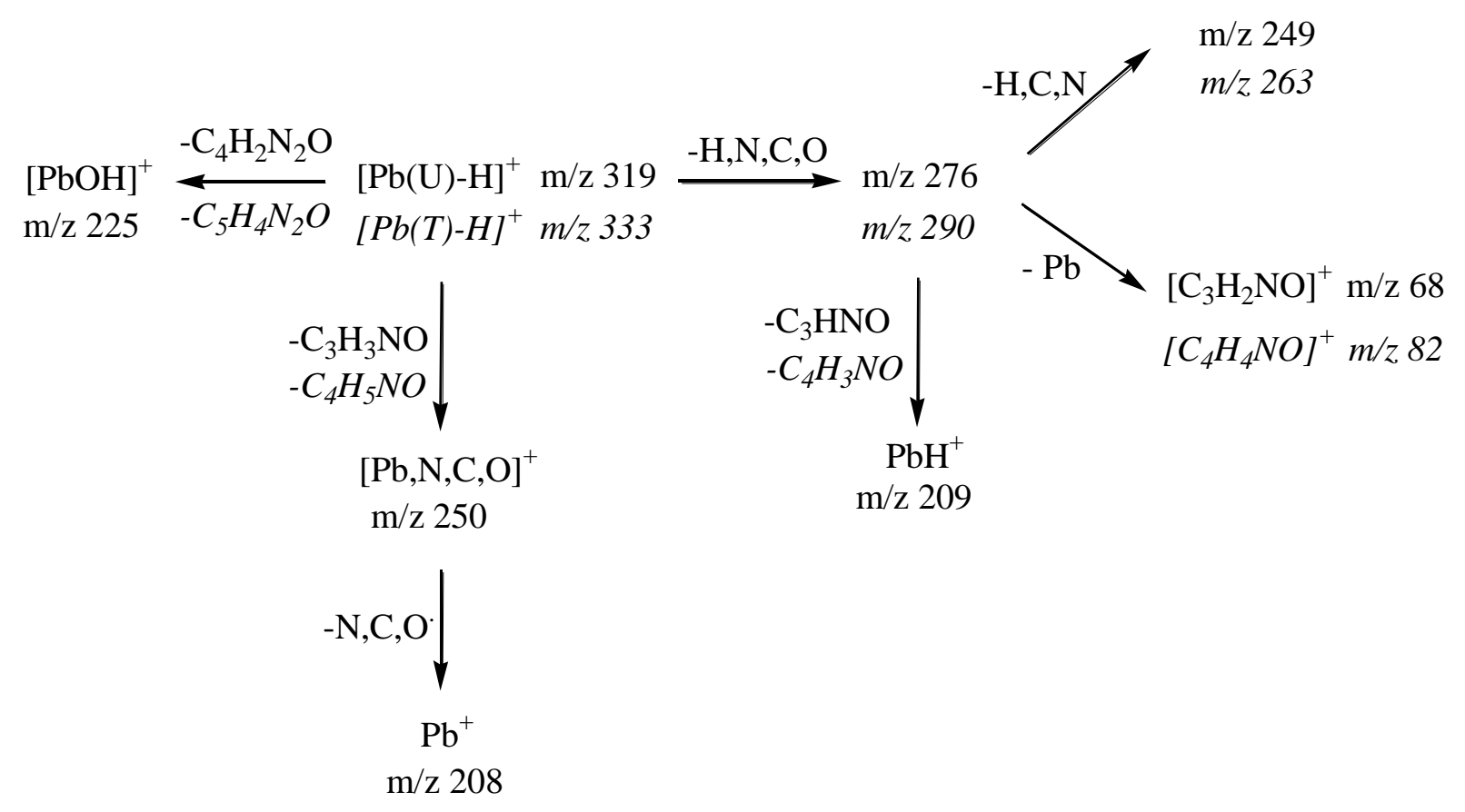

Scheme 2

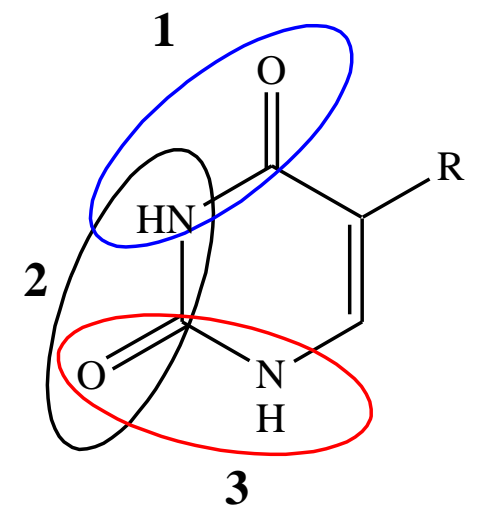

Scheme 3 